Atmos. Chem. Phys., 18, 17545-17572, 2018

https://doi.org/10.5194/acp-18-17545-2018

(C) Author(s) 2018. This work is distributed under

the Creative Commons Attribution 4.0 License.

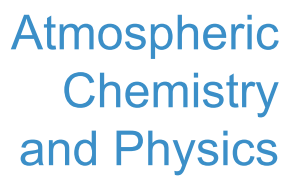

(c) (P)

\title{
The impact of mineral dust on cloud formation during the Saharan dust event in April 2014 over Europe
}

\author{
Michael Weger ${ }^{1}$, Bernd Heinold ${ }^{1}$, Christa Engler ${ }^{2, a}$, Ulrich Schumann ${ }^{6}$, Axel Seifert ${ }^{4}$, Romy Fößig ${ }^{3}$, \\ Christiane Voigt $^{6,7}$, Holger Baars ${ }^{1}$, Ulrich Blahak ${ }^{4}$, Stephan Borrmann ${ }^{7,8}$, Corinna Hoose ${ }^{3}$, Stefan Kaufmann ${ }^{6}$, \\ Martina Krämer ${ }^{5}$, Patric Seifert ${ }^{1}$, Fabian Senf ${ }^{1}$, Johannes Schneider ${ }^{8}$, and Ina Tegen ${ }^{1}$ \\ ${ }^{1}$ Leibniz Institute for Tropospheric Research, Leipzig, Germany \\ ${ }^{2}$ Leipzig Institute for Meteorology, University of Leipzig, Leipzig, Germany \\ ${ }^{3}$ Institute of Meteorology and Climate Research, Karlsruhe Institute of Technology, Karlsruhe, Germany \\ ${ }^{4}$ Deutscher Wetterdienst, Offenbach, Germany \\ ${ }^{5}$ Forschungszentrum Jülich, Jülich, Germany \\ ${ }^{6}$ Deutsches Zentrum für Luft- und Raumfahrt, Institut für Physik der Atmosphäre, Oberpfaffenhofen, Germany \\ ${ }^{7}$ Johannes Gutenberg-Universität, Mainz, Germany \\ ${ }^{8}$ Max-Planck-Institut für Chemie, Mainz, Germany \\ aformerly at: Leibniz Institute for Tropospheric Research, Leipzig, Germany
}

Correspondence: Bernd Heinold (heinold@ tropos.de)

Received: 5 July 2018 - Discussion started: 2 August 2018

Revised: 15 November 2018 - Accepted: 19 November 2018 - Published: 11 December 2018

\begin{abstract}
A regional modeling study on the impact of desert dust on cloud formation is presented for a major Saharan dust outbreak over Europe from 2 to 5 April 2014. The dust event coincided with an extensive and dense cirrus cloud layer, suggesting an influence of dust on atmospheric ice nucleation. Using interactive simulation with the regional dust model COSMO-MUSCAT, we investigate cloud and precipitation representation in the model and test the sensitivity of cloud parameters to dust-cloud and dust-radiation interactions of the simulated dust plume. We evaluate model results with ground-based and spaceborne remote sensing measurements of aerosol and cloud properties, as well as the in situ measurements obtained during the ML-CIRRUS aircraft campaign. A run of the model with single-moment bulk microphysics without online dust feedback considerably underestimated cirrus cloud cover over Germany in the comparison with infrared satellite imagery. This was also reflected in simulated upper-tropospheric ice water content (IWC), which accounted for only $20 \%$ of the observed values. The interactive dust simulation with COSMO-MUSCAT, including a two-moment bulk microphysics scheme and dust-cloud as well as dust-radiation feedback, in contrast, led to significant improvements. The modeled cirrus cloud cover and
\end{abstract}

IWC were by at least a factor of 2 higher in the relevant altitudes compared to the noninteractive model run. We attributed these improvements mainly to enhanced deposition freezing in response to the high mineral dust concentrations. This was corroborated further in a significant decrease in ice particle radii towards more realistic values, compared to in situ measurements from the ML-CIRRUS aircraft campaign. By testing different empirical ice nucleation parameterizations, we further demonstrate that remaining uncertainties in the ice-nucleating properties of mineral dust affect the model performance at least as significantly as including the online representation of the mineral dust distribution. Dustradiation interactions played a secondary role for cirrus cloud formation, but contributed to a more realistic representation of precipitation by suppressing moist convection in southern Germany. In addition, a too-low specific humidity in the 7 to $10 \mathrm{~km}$ altitude range in the boundary conditions was identified as one of the main reasons for misrepresentation of cirrus clouds in this model study. 


\section{Introduction}

The Mediterranean and Europe are frequently affected by outbreaks of mineral dust, as specific atmospheric circulation patterns over northern Africa and the Mediterranean cause wind-driven dust emissions over the Sahara and consecutive transport to the north (e.g., Barkan et al., 2005; Salvador et al., 2014). Estimates of annual northern African dust emissions range from 400 to $2200 \mathrm{Tg}$ (Huneeus et al., 2011), of which about $10 \%$ are exported to Europe (Shao et al., 2011).

Mineral dust is an important aerosol constituent (Carslaw et al., 2010), which influences atmospheric processes. The dust particles scatter and absorb solar radiation as well as absorb and re-emit terrestrial radiation (e.g., Müller et al., 2011; Köhler, 2017), which alters the atmospheric stratification and thus can also impact cloud and precipitation formation (Chaboureau et al., 2011; Wang et al., 2013). Moreover, mineral dust particles directly participate in cloud microphysical processes by acting potentially as cloud condensation nuclei (CCN) (Bégue et al., 2015; Karydis et al., 2011) and icenucleating particles (INPs) (DeMott et al., 2003, 2010; Boose et al., 2016).

Based on numerous field and laboratory experiments, a variety of empirical relations to describe the ice-nucleating properties of mineral dust for application in numerical weather prediction (NWP) models have been developed so far (e.g., Phillips et al., 2008; Niemand et al., 2012; Hiranuma et al., 2014; DeMott et al., 2015; Ullrich et al., 2017). The impact of dust particles on cloud microphysical and macrophysical properties cannot be generalized as it depends on the cloud type considered, the background aerosol composition and meteorological conditions. In mixed-phase clouds, midtropospheric aerosol entrainment is important to consider (Fridlind et al., 2004), and additional INPs likely accelerate cloud glaciation and precipitation formation and finally shorten cloud lifetime (DeMott et al., 2010).

Cirrus clouds form either by lifting of liquid or mixedphase clouds across the homogeneous freezing threshold of $235 \mathrm{~K}$ (liquid origin) or in situ by a combination of heterogeneous and homogeneous ice nucleation of super cooled liquid aerosol (in situ origin) (Luebke et al., 2016; Krämer et al., 2016). If homogeneous nucleation is primarily involved in the formation of cirrus originating in situ, ice particle concentrations are determined by this process, with a negative correlation between INP concentrations and ice particle concentrations, cloud albedo and emissivity (negative Twomey effect, e.g., Kärcher and Lohmann, 2003). If, however, lifting occurs at low vertical velocities, supersaturation over ice may never exceed the threshold for homogeneous freezing. In this case, ice nucleation is determined by deposition freezing of INPs, with the occurrence of the positive Twomey effect in cirrus originating in situ (Krämer et al., 2016).

As a result of the various atmospheric interaction modes of dust particles, the weather is likely affected by outbreaks of Saharan dust over Europe. It has been shown in various studies using remote sensing observations that there is a robust correlation between the presence of mineral dust and the efficiency of ice formation, as well as the ice water content (IWC) in ice clouds (Seifert et al., 2010; Zhang et al., 2018; Zhao et al., 2018). In addition, there is also direct observational evidence of mineral dust interacting with cloud microphysics and dynamics inside dust-infused baroclinic cyclone storm clouds, as affected cirrus shields present with a visible cumuliform texture, exceedingly low cloud-top temperatures and other peculiar optical properties indicative for the presence of small ice crystals (Fromm et al., 2016). Similar findings have emerged from model studies. For example, Lee and Penner (2010) found a positive correlation between INP concentrations and ice particle number concentrations, as well as ice water path (IWP), by considering ice nucleation of dust and black carbon in the GCE (Goddard Cumulus Ensemble) model. It is well known that dust particle number concentrations can exceed the climatological mean value by a 100 -fold over a wide tropospheric height range during a dust event (Hande et al., 2015). In most operational NWP models, however, aerosol interactions are parameterized using preset aerosol concentrations and characteristics (e.g., the Integrated Forecast System (IFS) radiation scheme uses aerosol climatology from Tegen et al., 1997, and cloud droplet and ice particle number concentrations are predefined according to an assumed aerosol background; ECMWF, 2017). Obviously, these models are challenged during those outbreaks and the forecast performance is found to be significantly reduced in the presence of mineral dust (Schumann et al., 2016). In the past, studies with interactive dust modeling approaches were conducted to quantify the effects of desert dust on weather. Smoydzin et al. (2012) included cloud activation and ice nucleation of mineral dust (diagnostically by the DeMott et al., 2010, parameterization) in the coupled chemistry model WRF-Chem (Weather Research and Forecasting model - Chemistry) to simulate eastern Mediterranean dust outbreaks. Bangert et al. (2012) used the more detailed ice nucleation scheme by Barahona and Nenes (2009) with INP properties from Phillips et al. (2008) to include the competition of heterogeneous and homogeneous ice nucleation for cirrus cloud formation in their simulations of a major dust outbreak over Europe in 2008 with the regional dust model COSMO-ART (Consortium for Smallscale Modeling - Aerosols and Reactive Trace gases). Both studies found changes in mixed-phase cloud microphysics due to mineral dust to various degrees, e.g., more efficient cloud glaciation and a decrease in ice particle radii. Using ICON-ART (Icosahedral Nonhydrostatic - Aerosols and Reactive Trace gases) with a similar setup to that of Bangert et al. (2012), Rieger et al. (2017) modeled the dust outbreak over Europe in early April 2014 in order to estimate the considerably negative impact of dust-radiation, dust-cloud and combined effects on photovoltaic power generation.

The April 2014 Saharan dust outbreak is also the subject of this modeling study. During this event, various cloud systems 
were present, but most notably, an unusually extensive cirrus canopy occurred. The coincidence of these cloud conditions with the dust plume make it an interesting case to investigate the impact of mineral dust on cloud formation. For the investigation, we use interactive regional dust transport modeling with COSMO-MUSCAT (Consortium for Small-scale Modeling - MUltiScale Chemistry Aerosol Transport) (Wolke et al., 2004, 2012). Particular focus is put on the treatment of heterogeneous ice nucleation of mineral dust. Specifically we investigate (1) how well cloudiness and precipitation are represented in the COSMO model with the operational radiation and single-moment bulk microphysics parameterizations without considering dust feedback, (2) whether considering dust-cloud and dust-radiation interactions with a twomoment microphysics scheme improves cloud and precipitation representation, and if so, (3) how important the role of isolated interaction processes therein is, and (4) how the choice of the INP parameterization influences the model results. Based on the answers to these questions, we further seek to improve our understanding of cloud formation during the Saharan mineral dust event. We use a comprehensive observational data set for model evaluation. It consists of standard satellite and ground-based remote sensing, and the unique, rich data set of the campaign ML-CIRRUS (Voigt et al., 2017), consisting of airborne in situ measurements. The present study thus expands the work of Rieger et al. (2017), as it puts the focus on a detailed evaluation of cloud properties during the dust outbreak.

The paper is structured as follows: in Sect. 2, the interactive dust-transport model COSMO-MUSCAT is described together with the setup of sensitivity model runs, and an overview of the observational data available for evaluation is given. Section 3 contains a synoptic overview of the Saharan desert dust outbreak in April 2014. In Sect. 4, the model results are presented in comparison with the available observational data and a more detailed discussion of the dust impact on cloud microphysics and cloud development is given. Finally, in Sect. 5 the main outcomes of the study are summarized, followed by the conclusion.

\section{Methodology}

\subsection{Model description}

For the simulations of dust transport and the effects on cloud development, the chemistry transport model MUSCAT (Wolke et al., 2004, 2012) is used, online-coupled to the nonhydrostatic regional NWP model COSMO; version 5.0, of the German Weather Service (DWD) (Doms and Baldauf, 2015).

\subsubsection{Operational model configuration}

A detailed description of the physical parameterizations applied in the operational version of COSMO can be found in Doms (2008) and Doms et al. (2011). For the treatment of cloud processes and precipitation formation an efficient single-moment bulk water-continuity scheme is used, which considers cloud water, rain, cloud ice, snow and optionally graupel (not used here) as hydrometeor classes. Conversion processes between these classes, as well as cloud condensation and ice formation, are formulated by simple and efficient parameterizations, which do not account explicitly for the impact of a quantifiable aerosol concentration on these processes (i.e., they assume the ubiquitous presence of aerosol particles). As a result, cloud condensation and cloud evaporation is treated by performing saturation adjustment, which is the redistribution of the equivalent amount of water to restore thermodynamic equilibrium between liquid water and water vapor. This approach is reasonable for warm clouds. In mixed-phase clouds, however, ice nucleation and ice particle growth occurs outside thermodynamic equilibrium, and both processes are therefore parameterized in more detail in COSMO. The underlying assumption therein is an empirical relationship between the ice particle number concentration $n_{\mathrm{i}}$ and the temperature $T$, which is a fit to aircraft data from Hobbs and Rangno (1985) and Meyers et al. (1992):

$n_{\mathrm{i}}=1 \times 10^{2} \mathrm{~m}^{-3} \exp [0.2(T-273.15 \mathrm{~K})]$.

Equation (1) is used to diagnose $n_{\mathrm{i}}$ as well as the mean diameter $D_{\mathrm{i}}$ in the growth equation (e.g., Pruppacher and Klett, 2010) for depositional growth and to deduce an ice nucleation rate for grid cells not containing any cloud ice $\left(q_{\mathrm{i}}=0\right)$ :

$\dot{q}_{\mathrm{i}, \text { nuc }}=\frac{n_{\mathrm{i}} m_{\mathrm{i}}^{0}}{\rho_{\mathrm{air}} \Delta t}$.

$\dot{q}_{\mathrm{i}, \text { nuc }}$ is the mass mixing ratio transferred from the water vapor to the ice phase due to heterogeneous ice nucleation per time step $\Delta t$ and involves the assumption of an initial ice particle mass $m_{\mathrm{i}}^{0}=1 \times 10^{-12} \mathrm{~kg}$. $\rho_{\text {air }}$ is the density of air. Equation (2) is only applied if the grid cell temperature is lower than the onset temperature for ice formation $T_{\text {nuc }}=267.15 \mathrm{~K}$. Deposition freezing is limited to temperatures lower than $T_{\mathrm{d}}=248.15 \mathrm{~K}$, whereas for temperatures above $T_{\mathrm{d}}$, heterogeneous ice nucleation is the result of condensation freezing, which additionally requires water saturation.

Radiative transfer in COSMO is treated by a $\delta$-twostream scheme, calculating upward and downward shortwave and longwave fluxes in 3 and 5 spectral intervals, respectively (Ritter and Geleyn, 1992). To consider the effects of clouds on radiative transfer, a cloud fraction is parameterized, which encompassed contributions from grid-scale and subgrid-scale stratiform cloudiness as well as convective cloudiness. Accordingly, modified liquid and ice water mixing ratios $\left(q_{\mathrm{sc}, \mathrm{c}}\right.$ and $q_{\mathrm{sc}, \mathrm{i}}$ ), containing the subgrid-scale contributions, are derived, which are used to calculate optical 
properties of clouds. Most importantly, the generalized effective diameter $D^{\text {ef }}$ is directly related to $q_{\mathrm{sc}, \mathrm{c} / \mathrm{i}}$ via empirical formulations. Radiative transfer further depends on the vertical alignment of cloud-free and cloud-covered areas in adjacent layers. It is assumed that clouds have maximum overlap, unless there is an intermediate layer without any cloudiness. In this case clouds are distributed randomly. To include the effects of aerosols, a spatially variable climatological mean aerosol distribution is prescribed, with consideration of five different types of aerosol optical properties (maritime, continental, urban, volcanic and background stratospheric).

\subsubsection{Dust scheme}

Dust emission and transport are computed by the multiscale transport model MUSCAT, including the parameterization of dust emission and deposition fluxes given in Heinold et al. (2007), Heinold et al. (2011) and Schepanski et al. (2017). Mineral dust is transported as a passive tracer in five size bins with the particle diameter limits at 0.2, 0.6, 1.8, 5.2, 16 and $48 \mu \mathrm{m}$. For dust advection, in MUSCAT, a third-order upstream scheme is used along with an implicit-explicit integration scheme (Knoth and Wolke, 1998; Wolke et al., 2000). The dust source scheme is based on the work of Tegen et al. (2002) and includes the parameterization of the threshold friction velocity $u_{\mathrm{t}}^{*}$ for particle mobilization. $u_{\mathrm{t}}^{*}$ is dependent on the soil particle size distribution (Marticorena and Bergametti, 1995), which is resolved in four size classes (coarse sand, medium/fine sand, silt and clay) and the surface roughness length $z_{0}$. To account for the effect of vegetation on dust emission, 27 different vegetation types are considered. Vegetation cover is further parameterized according to Knorr and Heimann (1995), using satellite-based normalized difference vegetation index (NDVI) data sets (Tucker et al., 2005). Based on the vegetation type and cover as well as snow cover, an effective area $A^{\text {ef }}$ for dust emission is calculated. Soil moisture content, derived from the hydrological fields of COSMO, is assumed to suppress dust emission, if exceeding $99 \%$. The frictional velocity $u_{*}$ is calculated from COSMO first-layer winds using surface roughness data from satellite retrievals (Prigent et al., 2012). If $u_{*}>u_{\mathrm{t}}^{*}$, dust emission is allowed and computed with a cubic function of $u_{*}$ (Heinold et al., 2007). The potential areas of dust emission are prescribed using a dust source activation frequency mask. This is derived from Meteosat Second Generation (MSG) Spinning Enhanced Visible and InfraRed Imager (SEVIRI) dust index observations (Schepanski et al., 2017). Dust removal is treated as dry (Zhang et al., 2001) and wet deposition, while the latter considers in-cloud and below-cloud scavenging (Berge, 1993; Jacobson, 1997; Jonson et al., 1998).

Comparisons with results from field studies show that the model provides a good representation of the different aspects of the atmospheric dust cycle (e.g., Heinold et al., 2011).

\subsubsection{Dust-cloud interactions}

For the interaction of simulated dust with clouds, the two-moment bulk microphysics scheme of Seifert and Beheng (2006) as also implemented in COSMO was modified to include the effects of a variable mineral dust concentration on cloud activation and heterogeneous ice nucleation. In past modeling studies, aerosol scavenging by activation and aerosol processes inside clouds was usually not considered (e.g., Bangert et al., 2011). As a consequence, cloud freezing had to be treated stochastically only depending on cloud droplet number concentrations but not on a variable aerosol concentration (Bangert et al., 2012). Field studies, however, have shown a variable interstitial aerosol fraction increasing toward the cloud edges (Gillani et al., 1995) or in the presence of ice particles (Verheggen et al., 2007). In this work, for a detailed description of in-cloud droplet activation as well as ice nucleation (immersion, contact and deposition nucleation), the aerosol concentration $n_{\mathrm{a}}$ is partitioned into an interstitial $n_{\text {in }}$ and cloud-water-scavenged component $n_{\mathrm{sc}}$. Aerosol species considered are mineral dust, soot and organics, while the latter two classes are given by prescribed number concentrations (see Table 2). The cloud number concentration $n_{\mathrm{c}}$ is used to determine $n_{\mathrm{sc}}$, and accordingly if $n_{\mathrm{c}}>n_{\mathrm{a}}, n_{\mathrm{sc}}=n_{\mathrm{a}}$, otherwise $n_{\mathrm{sc}}=n_{\mathrm{c}}$. In the latter case, the five particle size bins are partitioned by applying weighting factors based on data of a case study report by Hallberg et al. (1994), which prioritize the larger particle classes.

Cloud droplet activation is parameterized according to Abdul-Razzak and Ghan (2000) for a multi-mode aerosol, consisting of different size classes and different chemical groups. The different chemical composition of dust, soot and organics is represented by different hygroscopicity parameters $\kappa$. We use the following set of hygroscopicity parameters for dust, soot and organics: $0.14,0.308,0.308$, respectively. The parameterization was originally developed for droplet activation at the cloud base, considering the competition of the different aerosol modes in an ascending air parcel. To modify the parameterization for in-cloud conditions, preexisting cloud droplets are considered as an additional competing aerosol mode with the size being the mean droplet diameter $D_{\mathrm{c}}$ and with $\kappa \approx 0$. Consequently, only the interstitial aerosol component is available for droplet activation.

Heterogeneous ice nucleation in our model is based on empirical parameterizations of the aerosol surface density of ice nucleation active sites (INASs) $n_{\text {IS }}\left(\mu \mathrm{m}^{-2}\right)$, presuming the validity of the singular hypothesis, which assumes instantaneous ice nucleation events occurring in response to a sufficient increase in supersaturation, as opposed to a more detailed stochastic ice nucleation model (see for example Niedermeier et al., 2011). For desert dust, we use the parameterization of Ullrich et al. (2017) as default, which can be considered as one of the most accurate to date. It is based on a comprehensive data set gathered by nucleation experiments, carried out in the Aerosol Interaction and Dynamics 
in the Atmosphere (AIDA) facility (Wagner et al., 2006), and a novel algorithm for data evaluation. It is considered to be an especially reliable parameterization for deposition nucleation as it shows the characteristic u-shape of INAS-density isolines, which is in accordance with more recent theoretical work on deposition nucleation (Marcolli, 2014). For soot and organics, we use the parameterization of Phillips et al. (2008), which is based on field studies.

Heterogeneous cloud droplet freezing is determined by the probability $P_{\mathrm{fr}}$ for a single cloud droplet to freeze; hence, after evolution of model time step $\Delta t$, the number of heterogeneously frozen droplets is as follows:

$\Delta n_{\mathrm{c}, \text { het }}=-n_{\mathrm{c}} P_{\mathrm{fr}}$.

$P_{\text {fr }}$ results from the combined probabilities for immersion $\left(P_{\text {im }}\right)$ and contact freezing $\left(P_{\mathrm{co}}\right)$ :

$P_{\mathrm{fr}}=1-\left(1-P_{\mathrm{im}}\right)\left(1-P_{\mathrm{co}}\right)$.

In a first-order approximation, $P_{\mathrm{co}}$ is proportional to the number of colliding interstitial aerosol particles with cloud droplets during evolution of model time step $\Delta t$. To parameterize the collision rate, the collision kernel $\Psi_{\mathrm{co}}^{l}$ of Ovtchinnikov and Kogan (2000) is used, which includes the attractive or repulsive forces of Brownian motion, thermophoresis and diffusiophoresis. It depends on the diameter of colliding particles, approximated here as the first moment of the cloud droplet particle size distribution (PSD) and the mean diameter of considered aerosol particle size bin $l$. In Eq. (5), it is summed over all aerosol indices for chemical class $k$ and size $l$.

$P_{\mathrm{co}}=\sum_{k, l} n_{\mathrm{in}}^{k, l} \Psi_{\mathrm{co}}^{l} P_{\mathrm{IN}}^{k, l} \Delta t$

$P_{\text {im }}$ results from immersed potential INPs, which activate if the temperature tendency $\Delta T=T(t+\Delta t)-T(t)$ is negative, which leads to a temporal increase in INP concentrations. $\Delta T$ is diagnosed using the grid-scale vertical velocity $w$ and the diagnostic vertical temperature gradient $\mathrm{d} T / \mathrm{d} z$, thus neglecting horizontal temperature advection. Only the scavenged aerosol component $n_{\mathrm{sc}}$ is available for immersion freezing:

$P_{\mathrm{im}}=\frac{1}{n_{\mathrm{c}}} \sum_{k, l} n_{\mathrm{sc}}^{k, l} \Delta P_{\mathrm{IN}}^{k, l}\left(T, \Delta T_{t}\right)$.

Both Eqs. (5) and (6) contain the probability $P_{\mathrm{IN}}$ of an aerosol particle to act as an INP, which is based on a Poisson distribution:

$P_{\mathrm{IN}}^{k, l}(T)=1-\exp \left\{-n_{\mathrm{IS}}\left[T, S_{\mathrm{i}}^{w}(T)\right] \omega^{k, l}\right\}$.
Therein the expectation value refers to the mean number of INASs per particle active at temperature $T$ and saturation over ice $S_{\mathrm{i}} . \omega^{k, l}$ is the mean aerosol surface of the considered aerosol mode. For contact and immersion freezing, $n_{\mathrm{IS}}$ is evaluated at water saturation, as indicated by $S_{\mathrm{i}}=S_{\mathrm{i}}^{w}(T)$. The freezing threshold for contact freezing was found to be about $4.5 \mathrm{~K}$ higher than for immersion freezing (Shaw et al., 2005), thus in the case of contact freezing a correction term $\Delta T_{\mathrm{co}}=4.5 \mathrm{~K}$ is applied in the calculation of $n_{\mathrm{IS}}$. For contact freezing, colliding aerosol particles are represented by a population of completely inactivated aerosol particles. For immersion freezing, however, the fraction of already frozen INPs needs to be taken into account by calculating the increase in $P_{\mathrm{IN}}$ during $\Delta t$ :

$\Delta P_{\mathrm{IN}}\left(T, \Delta T_{t}\right)=\operatorname{Max}\left[0, P_{\mathrm{IN}}(T+\Delta T)-P_{\mathrm{IN}}(T)\right]$.

Deposition freezing of water vapor on interstitial aerosol particles predominantly takes place in pure ice clouds at $S_{\mathrm{i}}>1$ and $T<235 \mathrm{~K}$. These restrictions are not explicitly made here, as the empirical INP parameterizations for deposition freezing are also valid for higher temperatures. In most cases, however, cloud droplet freezing and deposition nucleation are not expected to occur simultaneously at significant rates, as at water saturation and for $T>235 \mathrm{~K}$ deposition nucleation is not efficient. The number of newly nucleated ice particles in the deposition freezing mode $\Delta n_{\mathrm{i} \text {, dep is calcu- }}$ lated diagnostically according to Seifert and Beheng (2006), as a balance equation for interstitial aerosol would be needed for a prognostical treatment (in opposition to cloud droplet freezing, where there is a balance equation for $n_{\mathrm{c}}$ ). Thus, $\Delta n_{\mathrm{i}, \text { dep }}$ is limited by the ice and snow particle number concentrations $n_{\mathrm{i}}$ and $n_{\mathrm{s}}$, respectively:

$\Delta n_{\mathrm{i}, \mathrm{dep}}=\operatorname{Max}\left(0, \sum_{k, l} n_{\mathrm{in}}^{k, l} P_{\mathrm{IN}}^{k, l}-n_{\mathrm{i}}-n_{\mathrm{s}}\right)$.

Finally, the number of heterogeneously frozen ice crystals due to ice nucleation $\Delta n_{\mathrm{i} \text {, het }}$ is given as the sum of heterogeneous cloud droplet freezing and deposition freezing:

$\Delta n_{\mathrm{i}, \text { het }}=-\Delta n_{\mathrm{c}, \text { het }}+\Delta n_{\mathrm{i}, \mathrm{dep}}$.

Homogeneous freezing of cloud droplets is treated as in Seifert and Beheng (2006), with a stochastic approach and a temperature-dependent freezing rate constant (Cotton and Field, 2002).

\subsubsection{Dust-radiation interactions}

The computation of short- and longwave radiative fluxes in COSMO considers scattering, absorption and re-emission by aerosols, cloud hydrometeors and trace gases. In interactive 
COSMO-MUSCAT simulations, it additionally takes into account the modeled size-resolved dust distribution (Helmert et al., 2007). The model thus considers the direct radiative impact and related dynamical feedbacks of the spatially and temporally varying atmospheric dust load. Dust optical thickness is calculated based on the modeled dust concentration by assuming spherical particles. The optical properties of Saharan dust are derived from Mie theory (Mishchenko et al., 2002) using refractive indices from Sinyuk et al. (2003).

In order to make use of the more detailed two-moment microphysics information, the single-moment microphysics approach of parameterizing cloud optical properties in Ritter and Geleyn (1992) was revised by Dipu et al. (2017). This way the impact of the spatially and temporally varying size of cloud droplets and ice crystals on cloud optical depth and reflectivity is also accounted for, by using the prognostic version of the effective diameter $D^{\text {ef }}$ of cloud droplets and ice crystals. For cloud ice, $D_{\mathrm{i}}^{\text {ef }}$ is defined by

$D_{\mathrm{i}}^{\text {ef }}=\frac{3 \text { IWC }}{2 \rho_{\mathrm{i}} \sigma_{\mathrm{i}}}$

(e.g., Mitchell et al., 2011), with the specific mass of ice $\rho_{\mathrm{i}}$, the water content IWC and the mean particle cross section $\sigma_{\mathrm{i}}$. Assuming shape parameters for ice particles, IWC and $\sigma_{\mathrm{i}}$ are directly computed from the prognostic variables $n_{\mathrm{i}}$ and $q_{\mathrm{i}}$ (and similarly for cloud water content LWC from $n_{\mathrm{c}}$ and $q_{\mathrm{c}}$ ), which should lead to a much more accurate representation of dust-cloud radiation effects in the model.

\subsection{Simulation setup}

COSMO-MUSCAT is applied on 2-fold nested domains, as depicted in Fig. 1, to simulate the Saharan dust outbreak in early April 2014 over Europe. The outer domain D1, which covers Europe and northern Africa, provides the emission and long-range transport of Saharan dust toward Europe, while the inner domain D2 is used for investigating the representation of cloudiness and precipitation over Germany. Domain D1 has a horizontal resolution of $14 \mathrm{~km}$, is divided into 40 vertical layers up to an altitude of $20 \mathrm{~km}$, and spans the area enclosed within $20^{\circ} \mathrm{N}, 20^{\circ} \mathrm{W}$ and $61.5^{\circ} \mathrm{N}, 39^{\circ} \mathrm{E}$. In this simulation, COSMO-MUSCAT is run with the operational single-moment bulk water continuity microphysics scheme and without dust-cloud interactions. However, interactive dust-radiation interactions according to Heinold et al. (2007) were considered. A Tiedtke (1989) convection scheme was used to treat subgrid-scale cloud and precipitation processes, related to moist convection, as horizontal resolution is not sufficient to explicitly resolve these processes. The dust simulation is run for the period 27 March to 6 April, in order to cover associated dust emissions and the development and evolution of the dust plume. COSMO is driven by initial and boundary fields from analysis of the global GME model of DWD. The simulations are re-initialized every $48 \mathrm{~h}$ to keep the model meteorology close to the real synoptic situation. One cycle consists of $24 \mathrm{~h}$ of meteorological simulation, followed by another $24 \mathrm{~h}$ of COSMO-MUSCAT dust simulation. This allows enough relaxation time for the meteorological fields after re-initialization, as only the second half of the cycle is evaluated. The dust distribution of the previous cycle is used to initialize the following cycle, respectively. The dependency of dust emission on surface winds is highly nonlinear. The modeled dust is therefore highly sensitive to uncertainties in surface and soil properties as well as predicted wind speed. In order to match satellite- and ground-based observations of dust optical thickness, the threshold velocity for dust mobilization is reduced by a factor of 0.63 .

For the simulation of dust-cloud interactions over central Europe, COSMO-MUSCAT is run on the inner domain D2 with $2.8 \mathrm{~km}$ resolution and with 50 vertical layers. The area spans the coordinate range enclosed within $48.3^{\circ} \mathrm{N}$, $4.0^{\circ} \mathrm{E}$ and $55.3^{\circ} \mathrm{N}, 13.0^{\circ} \mathrm{E}$. The simulation is started on 3 April 2014 at 00:00 UTC and run for $60 \mathrm{~h}$ without restart. COSMO is initialized and driven with hourly analysis data from the operational COSMO-DE run provided by DWD in order to use driving conditions that are closest to the actual weather situation and benefit from the finer grid spacing. The simulated dust fields of D1 are interpolated onto the D2 grid and used for initialization of the dust fields of D2, as well as for the 6-hourly updated lateral boundary conditions. The horizontal resolution of domain D2 is high enough to resolve moist deep convection. Nevertheless, subgrid-scale shallow convection needs to be parameterized by the restricted application of the scheme on this type of convection only, which is a common approach at this scale.

One D2 model run is performed with the single-moment bulk microphysics scheme as for D1. To ensure numerical stability of the microphysics schemes, the model integration time step is lowered to $10 \mathrm{~s}$ compared to the $25 \mathrm{~s}$ standard. Model evaluation is started after a model spin-up time of $24 \mathrm{~h}$ on 4 April 2014 at 00:00 UTC, which roughly coincides with the appearance of the dense cirrus canopy over Germany in the satellite images.

To evaluate the effects of the dust plume on cloud activation, ice nucleation and radiation, four additional model runs are carried out on D2, deploying the two-moment scheme by Seifert and Beheng (2006) with the modifications to allow for the online feedback of dust on cloud activation and ice nucleation. For ice nucleation of desert dust, the most up-todate INAS density parameterization of Ullrich et al. (2017) is chosen as default, while for the climatological background aerosol of soot and organics we rely on the parameterization of Phillips et al. (2008). A summary of the sensitivity model runs is given in Table 1, and parameters of the climatological mean aerosol PSD are listed in Table 2. The run ICLM is used to represent a climatological background dust scenario with two-moment microphysics, while IINT uses the simulated dust fields instead of the constant prescribed dust PSD. In RCLM and CCLM dust-radiation and dust-cloud activa- 


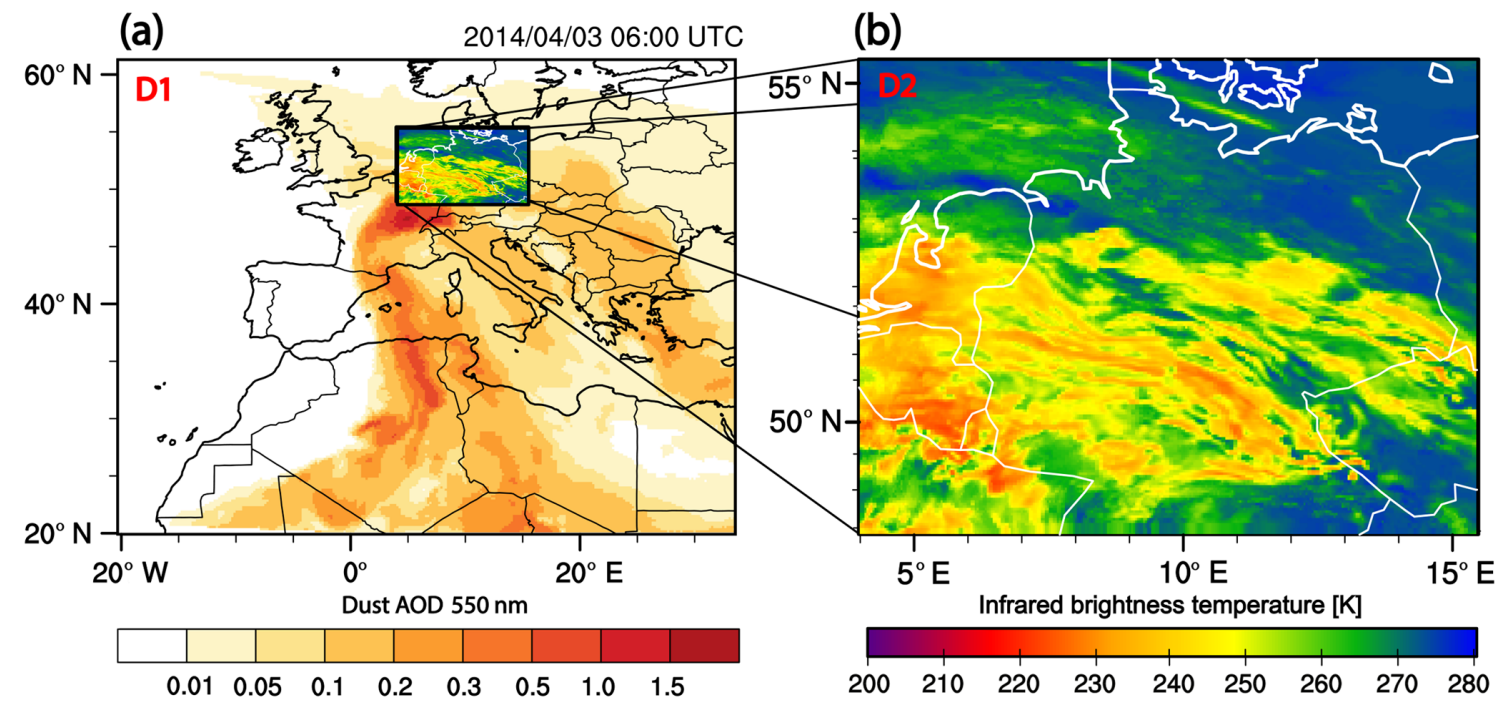

Figure 1. (a) Model simulation domain D1 with $14 \mathrm{~km}$ grid spacing showing dust AOD fields by COSMO-MUSCAT. (b) Inner model domain D2 with $2.8 \mathrm{~km}$ grid spacing showing simulated infrared brightness temperatures of a COSMO-MUSCAT run with interactive dust effects on cloud microphysics.

Table 1. Overview of the model runs performed in this study to investigate dust-cloud interactions (DCI) and dust-radiation interactions (DRI). CLM denotes the spatially and temporally fixed climatological mean dust concentration, INT indicates the interactively simulated dust concentration. U17 refers to the parameterization of Ullrich et al. (2017), and P08 to the parameterization of Phillips et al. (2008).

\begin{tabular}{llllll}
\hline Run & Purpose & $\begin{array}{l}\text { Dust INAS } \\
\text { density }\end{array}$ & $\begin{array}{l}\text { Dust } \\
\text { INP }\end{array}$ & $\begin{array}{l}\text { Dust } \\
\text { CCN }\end{array}$ & $\begin{array}{l}\text { Dust } \\
\text { radiation }\end{array}$ \\
\hline SMBLK & Reference, without DCI and RCI & - & - & - & - \\
ICLM & DCI and DRI at normal low dust conditions & U17 & CLM & CLM & CLM \\
IINT & DCI and DRI of simulated dust outbreak & U17 & INT & INT & INT \\
RCLM & Evaluate DRI of climatological dust & U17 & INT & INT & CLM \\
CCLM & Evaluate CCN effect of climatological dust & U17 & INT & CLM & INT \\
IAIP & Test alternative ice parameterization for dust & P08 & INT & INT & INT \\
\hline
\end{tabular}

tion is computed using the prescribed climatological mean dust concentration (modeled dust PSD, but with dust amount reduced to a spatially uniform low average value), respectively, in order to disentangle those effects of the simulated dust plume from the fully interactive effects seen in IINT. Finally IAIP is analogous to IINT, but uses the parameterization of P08 for ice nucleation of mineral dust.

\subsection{Observational data}

\subsubsection{Cloud radar observations}

To evaluate the modeled IWC, $94 \mathrm{GHz}$ spaceborne and $35 \mathrm{GHz}$ ground-based cloud radar observations are used. From the model side, the mixing ratios of cloud ice $\left(q_{\mathrm{i}}\right)$, snow $\left(q_{\mathrm{s}}\right)$, graupel $\left(q_{\mathrm{g}}\right)$ and the subgrid-scale ice $\left(q_{\mathrm{i}, \mathrm{sc}}\right)$ have to be included. $q_{\mathrm{i} \text {, sc }}$ is parameterized with a relative humidity scheme and the stratiform cloud fraction. By using the density of air, the values are converted to units $\left(\mathrm{g} \mathrm{m}^{-3}\right)$.
Observational data comprise a vertical cross section of IWC along a CloudSat satellite overpass on 4 April at 12:30 UTC (granules: 12457-42 209) with a horizontal along-track resolution of $1.7 \mathrm{~km}$ (data product 2B-CWCRO P_R04, Austin et al., 2009). To compare these data to model results, overflown grid cells are extracted from the D2 domain and observations are interpolated onto this array. Furthermore, vertical coordinate transformation to the 51 layer boundary heights of COSMO-MUSCAT is carried out, by averaging over all observations located within the corresponding model layer. Finally, horizontal grid-cell averages are computed for both observational and model data.

In addition to the CloudSat profile, a time series of vertical profiles of IWC retrieved from the $35 \mathrm{GHz}$ zenith pointing radar at Leibniz Institute for Tropospheric Research (TROPOS $)\left(51.3^{\circ} \mathrm{N}, 12.3^{\circ} \mathrm{E}\right)$ is available. The cloud radar of type Mira-35 (Görsdorf et al., 2015) is operated within the Leipzig Aerosol and Cloud Observations System (LACROS, Bühl et al., 2013), which comprises in addition an extensive set of 
Table 2. Aerosol size distribution for dust, soot and organics used in COSMO-MUSCAT for the climatological mean background. The number concentrations for dust are based on the temporal and spatial mean of simulated dust fields of a model run carried out on domain D2. The values for soot and organics are taken from Phillips et al. (2008), and accredited to the smallest size bin. The size bins are distributed logarithmically with a relative standard deviation of $\sigma=2$.

\begin{tabular}{lrlll}
\hline \multirow{2}{*}{$\begin{array}{l}\text { Size } \\
\text { bin }\end{array}$} & Mean volume & \multicolumn{3}{c}{ Number concentration $\left(\mathrm{m}^{-3}\right)$} \\
\cline { 3 - 5 } & diameter $(\mu \mathrm{m})$ & Dust & Soot & Organics \\
\hline 1 & 0.39 & $1.10 \times 10^{5}$ & $1.50 \times 10^{7}$ & $1.77 \times 10^{8}$ \\
2 & 1.17 & $5.02 \times 10^{4}$ & - & - \\
3 & 3.53 & $2.00 \times 10^{3}$ & - & - \\
4 & 10.65 & $2.18 \times 10^{2}$ & - & - \\
5 & 32.16 & $2.36 \times 10^{-6}$ & - & - \\
\hline
\end{tabular}

active and passive ground-based remote sensing instrumentation, such as lidar (PollyXT, Engelmann et al., 2016), a microwave radiometer (HATPRO, Rose et al., 2005) and an optical disdrometer. The observations of LACROS are automatically processed within Cloudnet (Illingworth et al., 2007) based on which a hydrometeor and aerosol target categorization is derived. Cloudnet provides output with a temporal and vertical resolution of $30 \mathrm{~s}$ and $30 \mathrm{~m}$, respectively. The Cloudnet target classification builds the basis for the retrieval of products such as liquid water content and ice water content. The ice water content is derived for all identified ice-only measurement points based on a parameterization of Hogan et al. (2006) that uses an empirical relationship between ice water content, temperature and radar reflectivity factor. In order to compare these data to equivalent model results, in a first step the original data set is averaged over variable time periods around the dates of the model output with $15 \mathrm{~min}$ intervals. The number of measurements to include in a single averaging procedure is given by horizontal advection and is therefore calculated based on the horizontal grid spacing of $2.8 \mathrm{~km}$ and the modeled horizontal wind speed. After vertical coordinate transformation, the obtained data sets are time averaged over the period from 4 April at 00:00 UTC to 5 April at 12:00 UTC.

\subsubsection{Infrared satellite imagery}

Model output fields of the hydrometeor mixing ratios, as well as thermodynamic variables, are supplied to an infrared (IR) forward simulation (see Appendix A for a detailed description). Resulting synthetic infrared images can be compared to satellite images obtained with the Spinning Enhanced Visible and Infrared Imager (SEVIRI) instrument aboard Meteosat Second Generation (MSG) satellite and provided by EUMETSAT (https://www.eumetsat.int, last access: 5 December 2017). For the atmospheric window channel at $8.7 \mu \mathrm{m}$, brightness temperature is used as a proxy for the cloud-top temperature of optically dense clouds, and further as a measure of cloud-top height.

\subsubsection{Precipitation records}

For Germany and closely surrounding areas, hourly precipitation totals are available for a total of 970 stations. The data are provided by the Climate Data Center (CDC) of the German weather service DWD (http://www.dwd.de/cdc, last access: 9 May 2017). The data were integrated over the model evaluation period from 4 April 2014 at 00:00 UTC to 5 April 2014 at 12:00 UTC and are used to evaluate the modeled precipitation amount for the different model runs.

\subsubsection{Cloud microphysical measurements}

During the ML-CIRRUS campaign (Voigt et al., 2017), 16 flights were performed from 26 March to 15 April 2014 with the High Altitude and Long Range Research Aircraft (HALO). The campaign had the scope to investigate cirrus and contrail cirrus above Germany and western Europe with a novel in situ and remote sensing payload. For model evaluation, the flights conducted on 3 and 4 April provide valuable information on cloud microphysical and thermodynamic properties.

Cloud particle number concentrations for 3 April were measured with the particle spectrometer NIXE-CAPS (Baumgardner et al., 2001; Meyer, 2013), which consists of the cloud and aerosol spectrometer NIXE-CAS to measure size and concentration of particles in the diameter range between 0.61 to $50 \mu \mathrm{m}$, and the optical particle counter NIXECIP to measure particles in the diameter range of 15 to $945 \mu \mathrm{m}$ with $15 \mu \mathrm{m}$ resolution. On 4 April, data were not available for the NIXE-CIP instrument. For particle diameters larger than $25 \mu \mathrm{m}$, we therefore used available measurements from the Cloud Combination Probe (CCP) instrument (Weigel et al., 2016). In the size range $d<3 \mu \mathrm{m}$ the PSD contains mostly aerosol particles, while for the larger sizes ice particles dominate. Thus, we select this cutoff size to limit the ice PSD, but retain the smaller bins as useful aerosol measurements. According to the aircraft altitude, measurements were assigned to the corresponding vertical layer of COSMO-MUSCAT on D2. For each layer the horizontally averaged PSD was calculated. Measurements with nonsignificant particle concentrations $\left(n_{\mathrm{i}}<1 \mathrm{~m}^{-3}\right)$ were not considered. IWC was retrieved from the measured PSD, assuming empirical mass-diameter relationships according to Krämer et al. (2016) and using the arithmetic mean of the size bin limits. For a measurement, the sphere-equivalent mean diameter $D_{\mathrm{i}}$ can be obtained simply by

$D_{\mathrm{i}}=\left(\frac{\mathrm{IWC}}{n_{\mathrm{i}} \rho_{\mathrm{i}}}\right)^{\frac{1}{3}}$. 
The number-averaged diameter $\bar{D}_{\mathrm{N}}$ of an ensemble of measurements is then defined by

$\bar{D}_{\mathrm{N}}=\sum D_{\mathrm{i}} n_{\mathrm{i}} / \sum n_{\mathrm{i}}$

and similarly the IWC-averaged $\bar{D}_{\text {IWC }}$ is defined by

$\bar{D}_{\text {IWC }}=\sum D_{\mathrm{i}}$ IWC $/ \sum$ IWC.

To find comparable model data, for each HALO measurement a horizontal circle with radius $r=100 \mathrm{~km}$ around the aircraft position is defined. The selection of this radius is justified, when considering the large impact of randomness on the distribution of clouds in the model at this length scale. Within this circle and at the model layer in which the aircraft is situated, the closest grid cell to the aircraft position is taken, which further has a grid-cell average IWC value in the same order of magnitude as that of the respective measurement. For the comparison of IWC, both measured and modeled IWC, containing contributions from $q_{\mathrm{i}}$ and $q_{\mathrm{s}}$, are discretized in nine levels. If there is no grid cell meeting this criterion, the respective measurement is excluded from a direct comparison with model results. By this approach, the codependence of $D_{\mathrm{i}}$ on IWC is taken into account, as well as to some extent the geographical codependence, which increases the significance of the comparison. For different model runs, however, the resulting number of data pairs can be different, as clouds are differently distributed in the model runs. For the ML-CIRRUS flight on 4 April, this approach cannot be applied, as the HALO flight-track is located completely outside of the domain D2. Nevertheless, these observations are useful for comparison with data from the ML-CIRRUS flight conducted on 3 April.

\subsubsection{Humidity measurements}

To evaluate atmospheric water vapor content in the model, humidity measurements from the airborne mass spectrometer (AIMS) (Kaufmann et al., 2018) aboard HALO aircraft during ML-CIRRUS flight of 3 April are available. AIMS data provide an accuracy of between $7 \%$ and $15 \%$. In addition, for 4 April at 00:00 UTC, 4 April at 12:00 UTC and 5 April at 00:00 UTC, data sets of atmospheric soundings (source: University of Wyoming; http://weather.uwyo.edu/ upperair/sounding.html, last access: 8 September 2017) are used from the stations Essen $\left(51.40^{\circ} \mathrm{N}, 6.97^{\circ} \mathrm{E}\right)$, Norderney $\left(53.71^{\circ} \mathrm{N}, 7.15^{\circ} \mathrm{E}\right)$, Schleswig $\left(54.53^{\circ} \mathrm{N}, 9.55^{\circ} \mathrm{E}\right)$, Greifswald $\left(54.10^{\circ} \mathrm{N}, 13.40^{\circ} \mathrm{E}\right)$, Bergen $\left(52.81^{\circ} \mathrm{N}, 9.93^{\circ} \mathrm{E}\right)$, Lindenberg $\left(52.21^{\circ} \mathrm{N}, 14.12^{\circ} \mathrm{E}\right)$, Kümmersbruck $\left(49.43^{\circ} \mathrm{N}\right.$, $\left.11.90^{\circ} \mathrm{E}\right)$, Meiningen $\left(50.56^{\circ} \mathrm{N}, 10.38^{\circ} \mathrm{E}\right)$ and IdarOberstein $\left(49.70^{\circ} \mathrm{N}, 7.33^{\circ} \mathrm{E}\right)$. As of 2014 , radiosondes of the type Vasaila RS92-SGP had been operationally used in Germany, before they were replaced by the predecessor RS41 in 2017. The uncertainty of RS92-SGP for bias-corrected data is estimated with $5 \%$ of relative humidity according to Miloshevich et al. (2008). After conversion to specific humidity $\left(\mathrm{kg} \mathrm{kg}^{-1}\right)$, the data are considered to have similar accuracy to the AIMS measurements, at least for temperatures higher than $213.15 \mathrm{~K}$.

\subsubsection{Dust aerosol observations}

For dust model evaluation, a rich data set consisting of aircraft measurements with an optical particle counter (OPC GRIMM model 1.129) aboard HALO for the days 3 and 4 April, as well as sun photometer observations of aerosol optical depth (AOD) at 40 Aerosol Robotic Network (AERONET) (https://aeronet.gsfc.nasa.gov, last access: 12 March 2018, Holben et al., 1998) stations located in northern Africa and Europe is provided. In addition, at the TROPOS site, lidar measurements were conducted for the model time period, from which dust particle extinction profiles could be retrieved for 5 April (Baars et al., 2016). For the other days, cloudiness and other more complex aerosol layers prevented a reliable retrieval.

Like the cloud microphysical measurements, OPC measurements are also available for the flights on 3 April afternoon and 4 April morning and are considered for the same time period.

The OPC detects particles in a diameter range from $250 \mathrm{~nm}$ to $20 \mu \mathrm{m}$, although the upper size range is limited by the aircraft inlet to about $5 \mu \mathrm{m}$. Here, we use the number concentration of particles larger than $500 \mathrm{~nm}$ as a proxy for the presence of mineral dust particles. This implies that only the four largest size bins of the modeled dust PSD are used in the comparison.

Similarly, sun photometer measurements are affected by all types of aerosol, while COSMO-MUSCAT AODs only consider dust. Therefore, the coarse-mode AOD product (particle diameter $>500 \mathrm{~nm}$, level 2.0 quality) of AERONET (O’Neill et al., 2003) predominantly represents the dust fraction and is thus commonly used for evaluating dust-only model results. Modeled mass extinction coefficients are derived from the dust PSDs by using refractive indices of Sinyuk et al. (2003) based on Mie theory. With further vertical integration of the mass extinction coefficients, dust AOD values are obtained for comparison with AERONET data.

\section{Dust outbreak April 2014}

In early April 2014, a pronounced trough of low pressure was situated over the eastern Atlantic Ocean, placing western Europe under a recurrent southerly flow pattern. On 2 April, the trough propagated eastward, with the associated cold front reaching the Atlas Mountains at the MoroccanAlgerian border, where it initiated a small lee cyclone to the south of the mountain range. Consecutively, high surface winds caused large dust emissions in the afternoon on 


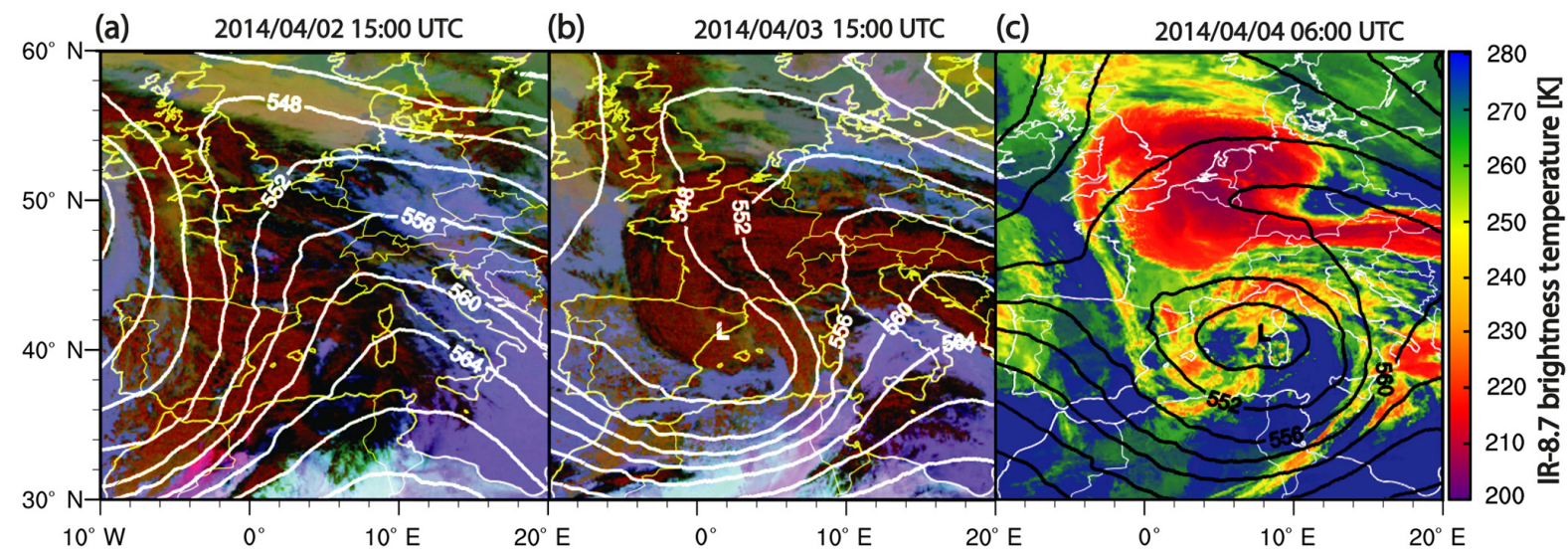

Figure 2. (a, b) Meteosat Second Generation (MSG) SEVIRI dust composite images for 2 April at 15:00 UTC and 3 April at 15:00 UTC, respectively. (c) MSG SEVIRI IR-8.7 brightness temperature for 4 April at 06:00 UTC. All images are overlaid with 500 hPa geopotential height contour lines from COSMO-MUSCAT $(14 \mathrm{~km})$ with 4 dam spacing.

2 April. Figure 2a shows the MSG IR false color dust index indicating dust presence by magenta and purple colored shadings. In addition, isolines of $500 \mathrm{hPa}$ geopotential height illustrate the synoptic situation at this time. The associated intense dust plume can be clearly identified from the magenta coloring over the Moroccan-Algerian border. Furthermore, the $500 \mathrm{hPa}$ geopotential height contour lines indicate air mass transport toward the western Mediterranean basin. Inside the warm conveyor belt (WCB), which closely goes ahead of the cold front, strong lifting caused the Saharan dust to eventually reach the upper troposphere, where it was further transported eastward behind the pronounced ridge axis. This transport mechanism was recently identified for a very similar case by Caffrey et al. (2018). Based on this analysis, a destination of the lifted dust over western and central Europe can be expected.

Over the next day, the eastward traveling cold front caused nearly continuous dust emissions (albeit weaker than the event in the afternoon on 2 April) over the desert in Algeria and Tunisia (see purple features in Fig. 2b). The persistence of the aforementioned flow pattern also favored most of this dust eventually reaching Europe on 3 April. With the development of an upper-level cutoff low over the western Mediterranean Sea and with its eastward movement, upperlevel winds over south-central Europe became more and more easterly on 4 April and, as a consequence, dust export from northern Africa to central Europe was not further supported. Ongoing upper-level lifting, especially at the northern boundary of the advancing Saharan mineral dust-rich air mass caused the development of extensive cirrus cloudiness. The horizontal extension as well as the high optical density of the cirrus shield became striking in the morning hours of 4 April, as associated cloud-top temperatures reached below $210 \mathrm{~K}$ over a large area, covering parts of France, Great Britain, the Benelux States and Germany (see Fig. 2c). A link of the high atmospheric mineral dust concentrations to this cloud development seems likely, as desert dust has excellent ice-nucleating abilities and furthermore it can destabilize the thermodynamic stratification of the atmosphere at the upper edge of the dust plume through interaction with radiation. Weak anticyclonic currents over central Europe kept the dust air mass and the associated cloudiness trapped until 5 April. In the evening hour an eastward-moving Atlantic cold front finally marked the end of the dust event, as skies cleared up due to the replacement of the dust air mass by subsiding clean air mass.

In the MSG imagery, cloud cover obscured most of the dust transport towards Europe. The horizontal dust distribution is better seen in the dust AOD maps (Fig. 3) from the COSMO-MUSCAT simulation at $14 \mathrm{~km}$ horizontal resolution. Figure $3 \mathrm{a}$ shows an intense dust plume with AOD exceeding 1.5 at the Moroccan-Algerian border on 2 April at 15:00 UTC, which corresponds to the magenta dust signature in the corresponding MSG IR image. Obviously, at this time, Europe was still affected by the remnants of a previous dust outbreak which occurred in late March 2014. In the consecutive image (Fig. 3b), the dust transport towards Europe is clearly depicted within the s-shaped conveyor belt. The initial dust plume is now located over Germany, with AOD values still reaching up to 1.5. Furthermore, the model reproduces the significant dust emissions in terms of dust AOD over the desert in Algeria and Tunisia in association with the eastward traveling cold front. In Fig. 3c, the closed circulation centered over Sardinia is clearly seen, with the freshly emitted dust over Libya being steered increasingly in a cyclonic gyre over the Mediterranean. Meanwhile the dust over central Europe is kept trapped, with the highest dust load found over Austria and southern Germany at AOD values up to 1. On 5 April at 12:00 UTC (Fig. 3d) the dust AOD over 
(a) $2014 / 04 / 02$ 15:00 UTC

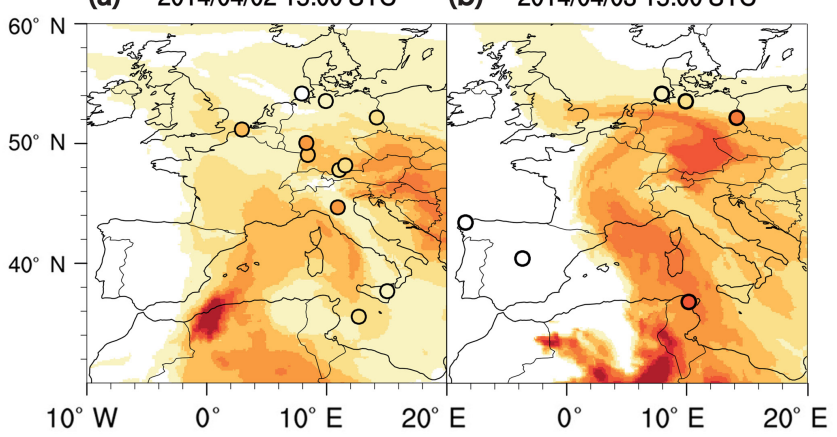

(c) 2014/04/04 12:00 UTC

(d) 2014/04/05 12:00 UTC
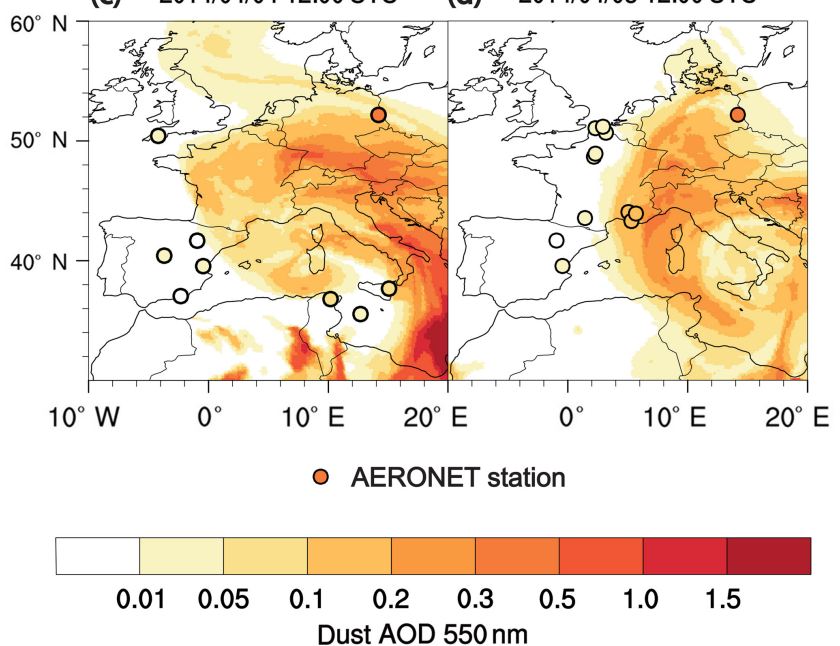

Figure 3. Maps of dust AOD at $550 \mathrm{~nm}$ as simulated with the dust transport model COSMO-MUSCAT on the D1 grid for 2 April at 15:00 UTC, 3 April at 15:00 UTC, 4 April at 12:00 UTC and 5 April at 12:00 UTC, respectively. AERONET observations of coarse-mode AOD at $500 \mathrm{~nm}$ are marked by colored circles.

Germany is markedly decreased but locally still reaches up to 0.5 .

The available AOD observations of AERONET stations (550 nm coarse mode, quality level 2.0) are depicted by colored circles in Fig. 3 for dust model evaluation. On 2 April at 15:00 UTC, observed AOD over Europe is already significantly raised (up to 0.5 ), which is similar to the model results. On 3 April at 15:00 UTC, observations show a strong zonal gradient in AOD, with strongly elevated values in Tunis and Lindenberg (Germany) (AOD up to 1) and moderately elevated values in northern Germany (AOD up to 0.3), while the Iberian peninsula was obviously not affected by dust $(\mathrm{AOD}<0.01)$. This is in very good agreement with the simulation. Over the next 2 days, there is a lack of observations over central Europe due to the obscuring cloudiness. However, the AERONET station at Lindenberg shows AOD values up to 0.5 on both 4 and 5 April at 12:00 UTC, which is higher than in the model, where the highest dust loads are displaced more to the south.

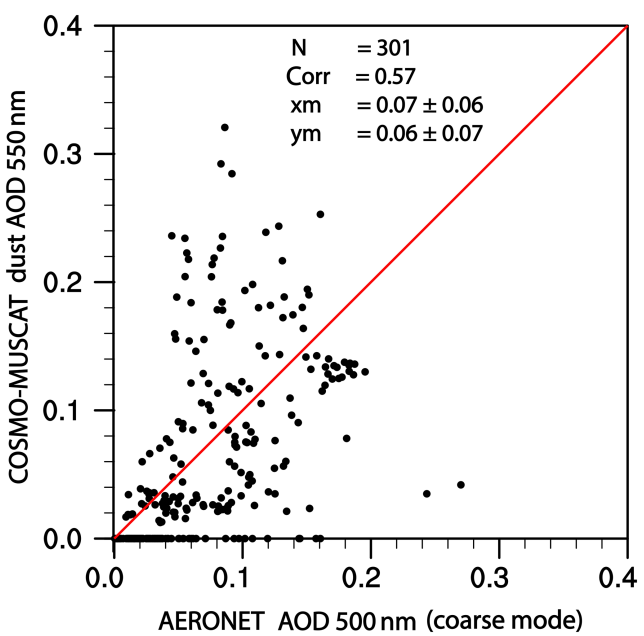

Figure 4. Scatter plot of observed $500 \mathrm{~nm}$ coarse-mode AOD and modeled dust AOD from the $14 \mathrm{~km}$ COSMO-MUSCAT run for all available AERONET stations within domain D1 (see Fig. 1). The data pool was gathered over the period from 2 April at 00:00 UTC to 6 April at 00:00 UTC by taking hourly model outputs and AERONET observations available within $\pm 0.5 \mathrm{~h}$ of corresponding time frames into account. Parameters printed are number of data points in each set $(\mathrm{N})$, correlation coefficient between both data sets (corr), mean of the observations (xm) and mean of modeled values (ym).

A statistical evaluation, taking AERONET coarse-mode AOD data of level 2.0 quality and corresponding modeled values at the nearest geographical position into account, is shown by the scatter plot in Fig. 4. The data set considered contains 301 observation-model pairs collected over the period 2 April at 00:00 UTC to 6 April at 00:00 UTC. Correlation between observational and model data is 0.57 . One has to note, however, that the number of observations directly affected by the dust plume was supposedly lower than usual, due to the extensive cloud cover. The mean AOD of both observations and model data does not differ significantly, as it is $0.07 \pm 0.06$ and $0.06 \pm 0.07$ respectively.

Concerning the vertical distribution of mineral dust, modeled dust fields are extracted along the flight paths of the HALO missions on 3 April afternoon and 4 April morning and compared to the OPC measurements in Fig. 5. On 3 April, a layer of aerosol with particles larger than $500 \mathrm{~nm}$ is located just below $7 \mathrm{~km}$, with particle number concentrations reaching up to $10^{7} \mathrm{~m}^{-3}$. Above this height, aerosol concentrations are mostly below the climatological mean dust concentration, showing that the dust plume did not expand into the upper troposphere on this day. The model shows similar high dust concentrations below $6 \mathrm{~km}$ altitude, but is not able to reproduce realistic dust concentrations above, as the upper edge of the dust plume is located above $9 \mathrm{~km}$ altitude. Supposedly, the model meteorology caused a too fast transport of the dust plume in the upper troposphere, as on the 


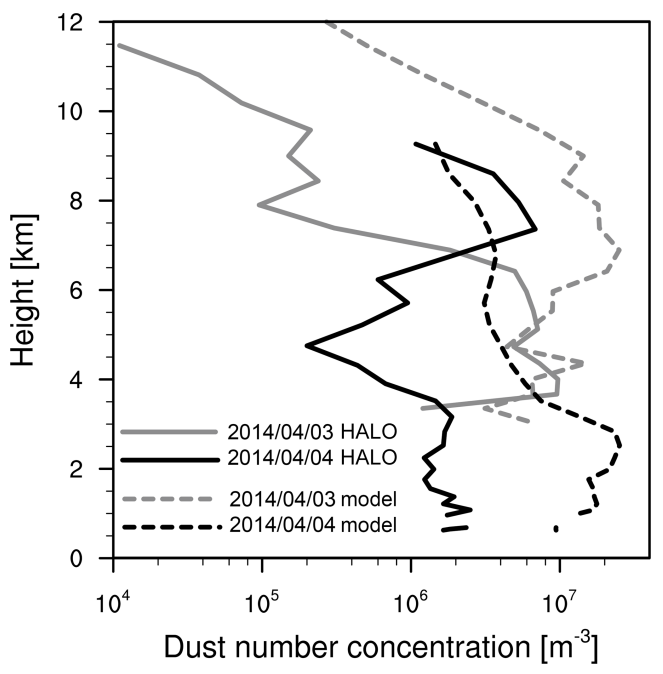

Figure 5. Vertical profiles of particle number concentration $(d>$ $500 \mathrm{~nm}$ as a proxy for dust) retrieved from aircraft measurements using an OPC and extracted model data along the flight paths shown in Fig. 14. Grey lines show data from 3 April 2014, black lines from 4 April 2014.

following day, measured aerosol concentrations caught up to typical values of a dust outbreak of $8 \times 10^{6} \mathrm{~m}^{-3}$, leading to a much better agreement between model and measurements. On the other hand, larger discrepancies persist in the lower and middle troposphere. However, here we have to note that the aircraft was in ascent and thus could not sample these altitudes over an adequate geographical distance in order to obtain a representative amount of data.

For 5 April, towards the end of the dust event, a vertical particle extinction coefficient profile, retrieved from lidar measurements (Baars et al., 2016) at TROPOS in Leipzig, provides further valuable information for dust model evaluation (Fig. 6). Although it was averaged only for a short time period around 5 April at 21:00 UTC, when the dust plume was moving eastward, it still shows mineral dust up to an altitude of $7 \mathrm{~km}$. Above this altitude, clean air had already subsided. According to the lidar particle extinction retrievals, the dust was located in two distinct layers. Associated peak values are well over 100 times the corresponding climatological mean value (see blue vertical line). The simulated extinction coefficient profile, which is computed from COSMO-MUSCAT dust concentrations using refractive indices taken from Sinyuk et al. (2003), is in good agreement, as it shows peak values of the same magnitude as well as the strong decline of mineral dust extinction above $6 \mathrm{~km}$ altitude. However, the layered structure is not well reproduced. Partly, this can be attributed to black carbon aerosol incorporation, which has very similar absorbing properties to mineral dust, in the lidar observations, which is not considered in the dust simulations by COSMO-MUSCAT. To a large extent, however, this is likely due to a too-strong vertical mixing and the

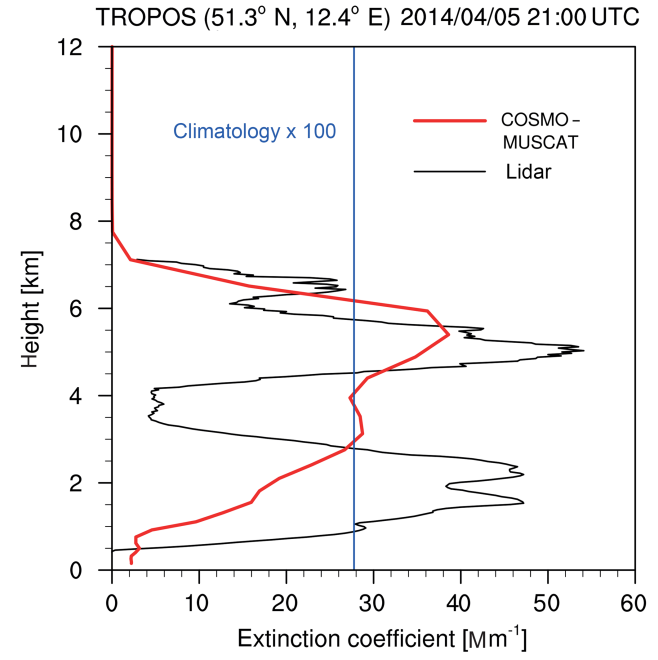

Figure 6. Vertical profile of aerosol extinction coefficient retrieved from lidar observations obtained at TROPOS in Leipzig on 5 April at 21:00 UTC, and calculated from the modeled dust fields at the nearest grid point.

potential incorporation of anthropogenic air pollutants within the boundary layer. COSMO-MUSCAT, on the other hand, only considers eolian mineral dust.

\section{Results}

\subsection{Reference model run SMBLK}

We first compare the model run SMBLK (see Table 1) with single-moment bulk microphysics and without dust feedback on clouds and radiation with the available observational data for an initial assessment of the representation of cloud cover, cloud microphysics and precipitation. For qualitative cloud cover comparison, we derived synthetic infrared satellite images by the application of the infrared forward simulator (see Appendix A) on the model data. Figure 7 shows maps of brightness temperature from MSG SEVIRI and the model run SMBLK over a $24 \mathrm{~h}$ period, starting on 4 April at 12:00 UTC. An extensive and optically dense shield of cirrus clouds traverses the domain in the satellite images. In some areas the associated cloud-top temperatures reach below $210 \mathrm{~K}$, which corresponds to the tropopause level. Most of this cloudiness is not present in the synthetic images of the model data, where it is mostly limited to the western and northern boundaries. These regions are strongly influenced by the driving boundary fields, as winds mostly prevailed from the west and north. Moreover, cloud-top temperatures of cloud fields present in the model are about $20 \mathrm{~K}$ too warm in comparison with the satellite images. In Fig. $7 \mathrm{~d}$ and $\mathrm{f}$, clouds are completely missing in the southeastern parts of the domain in the model results. 

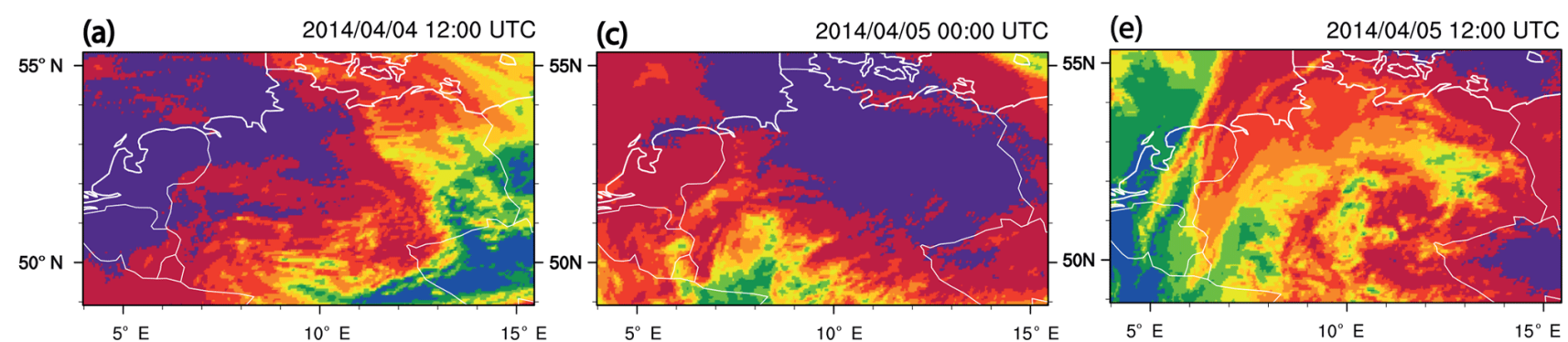

(b)

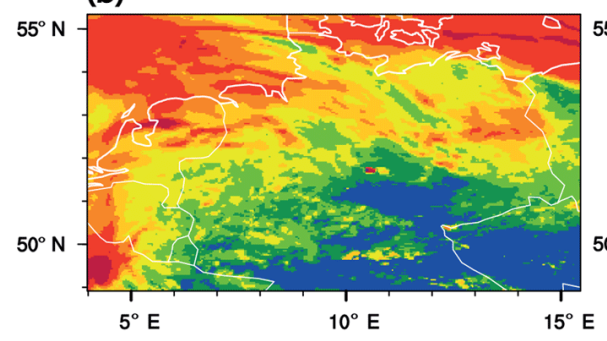

(d)

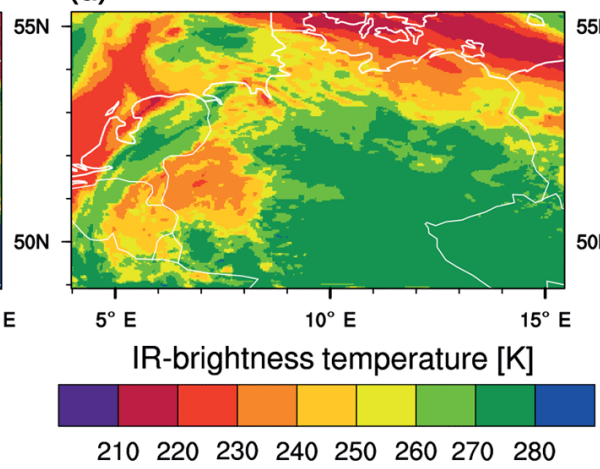

(f)

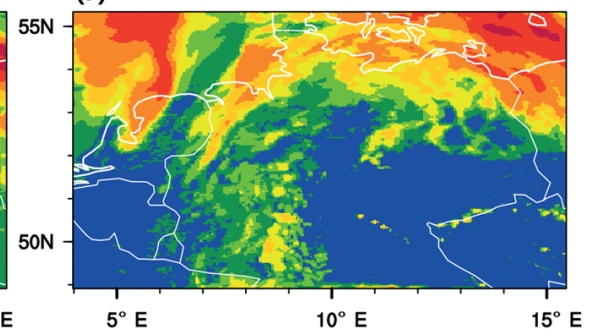

Figure 7. Infrared (IR; $8.7 \mu \mathrm{m}$ channel) brightness temperature maps based on (a, c, e) MSG SEVIRI data of EUMETSAT (a, c, e) and (b, d, f) on the infrared simulation with the model output fields of the run SMBLK.

Comparing the available CloudSat data to modeled IWC for the satellite overpass on 4 April around 12:30 UTC in Fig. 10a reveals a significant lack of IWC above an altitude of $6 \mathrm{~km}$ in the model. The discrepancy reaches up to 1 order of magnitude at $10 \mathrm{~km}$ altitude with a modeled value of $1 \times 10^{-3} \mathrm{~g} \mathrm{~m}^{-3}$ compared to $1 \times 10^{-2} \mathrm{~g} \mathrm{~m}^{-3}$ in the CloudSat retrieval. Moreover, cloud-top height in the model is significantly underestimated by about $1 \mathrm{~km}$. However, below $6 \mathrm{~km}$ altitude, the modeled along-track averages of IWC are in excellent agreement with observations. The horizontal distribution of mixed-phase clouds (not shown) differs considerably, as significant amounts of IWC occur to the north of $51^{\circ} \mathrm{N}$ in the observations, but not in the model. The comparison of the time series of IWC obtained with Cloudnet for the grid cell of the TROPOS site in Leipzig shows quite similar results (Fig. 10b). While IWC steadily increases above an altitude of $7 \mathrm{~km}$ and reaches up to $4 \times 10^{-3} \mathrm{~g} \mathrm{~m}^{-3}$ at $11 \mathrm{~km}$ altitude in the radar profile, the modeled profile shows IWC values fluctuating around $10^{-4} \mathrm{~g} \mathrm{~m}^{-3}$ in the same altitude range. However, below $6 \mathrm{~km}$, modeled IWC values are, at about $1 \times 10^{-2} \mathrm{~g} \mathrm{~m}^{-3}$, significantly higher than the observed values of $1 \times 10^{-3} \mathrm{~g} \mathrm{~m}^{-3}$. In summary, these results support the differences seen in the infrared image comparison, as both comparisons imply a substantial lack of IWC inside cirrus clouds. Cloud infrared absorption and thus simulated cloudtop temperatures are strongly dependent on IWC until saturation begins, in our case above a value of $5 \times 10^{-2} \mathrm{~g} \mathrm{~m}^{-3}$.

In addition, model precipitation amounts are evaluated, since they also may be affected by the effects of mineral dust.
Moreover, we can indirectly infer the distribution of precipitating mixed-phase clouds during the evaluation period, which is obscured in the satellite images (Fig. 2). In Fig. 11a, measured $36 \mathrm{~h}$ totals of precipitation (4 April at 00:00 UTC to 5 April at 12:00 UTC) at the various DWD stations in Germany and surrounding areas are compared to the model data. The highest amounts of up to $30 \mathrm{~mm}$ rain occurred in northern Germany, associated with a nearly stationary warm front. Other than that, isolated precipitation occurred partly triggered by orography, as well as in a curved band over western Germany, with totals mostly below $10 \mathrm{~mm}$. While the model agrees well in the maxima of precipitation in association with the warm front, the location of the precipitation band does not match the observations, as it is displaced too far to the northeast over the Baltic Sea $\left(54.5^{\circ} \mathrm{N}, 11.0^{\circ} \mathrm{E}\right)$. Even more remarkable is the occurrence of intense local precipitation of more than $30 \mathrm{~mm}$ in the model, linked with convection over western Germany on late 4 April, which was not observed at all. As a result, domain-wide precipitation is overestimated in the SMBLK run by $64 \%$.

Apart from the neglected effects of mineral dust, too-low humidity values might be the reason for the absence of cirrus clouds and IWC in the model. Figure 8a shows vertical profiles of specific humidity (SH) obtained by the AIMS instrument aboard HALO on the afternoon of 3 April, as well as by atmospheric soundings for 4 April at 00:00 UTC, 4 April at 12:00 UTC and 5 April at 00:00 UTC, respectively. The measurements show a general increase in SH over time, coinciding with the appearance of the cloud canopy. This in- 

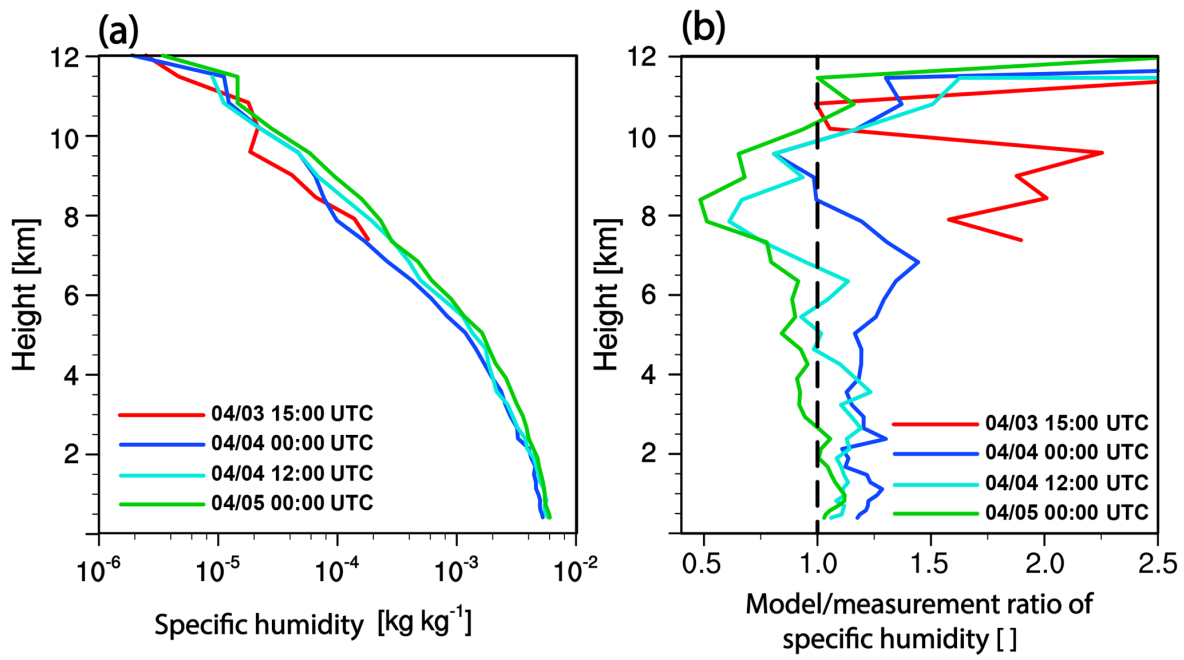

Figure 8. (a) Averaged vertical profiles of specific humidity ( $\mathrm{SH}$ ) obtained from atmospheric sounding at all stations located within the domain D2 for 4 April at 00:00 UTC, 4 April at 12:00 UTC and 5 April at 00:00 UTC, respectively, and from AIMS-H2O measurements aboard HALO for 3 April at 15:00 UTC. (b) Averaged model-measurement ratios of SH for same data as in (a).

crease in humidity is not reflected in the model results, as the model-to-measurement ratio in Fig. 8b shows a clear tendency of the model to become too dry compared to measurements over the simulation period. On 5 April at 00:00 UTC, there is a lack of up to $60 \% \mathrm{SH}$ at $8 \mathrm{~km}$ altitude. To rate the influence of this lack, we carried out a small sensitivity study, performing a model run with the same settings as in SMBLK, but with modified meteorological boundary fields. Therein, for a coarse adjustment, we raised specific humidity by a relative amount, which is determined by a Gaussian profile, centered at $8 \mathrm{~km}$ altitude. The added humidity is zero before 3 April at 18:00 UTC and then increases linearly over a $24 \mathrm{~h}$ period, with a constant value of $60 \%$ added from 4 April at 18:00 UTC. The humidity is not raised in the initial conditions, which is justified by the AIMS humidity measurements carried out on 3 April. The increase in humidity in the boundary fields resulted in a cooling of cloud tops and an increase in estimated cloud cover of roughly $50 \%$ in the time average from 4 April 00:00 UTC to 5 April 12:00 UTC, with the effect, however, being visible only toward the boundaries of the domain, while the center remains mostly unaffected (see Fig. 9 for a comparison on 5 April at 00:00 UTC). Probably, the additional humidity is rapidly absorbed by the present cloudiness, mainly for additional ice particle growth. This in turn would even decrease cloud lifetime, as sedimentation is enhanced. Given the comparison in Fig. 9, the decrease in simulated brightness temperatures, though substantial, can still not lead to an adequate representation of cloudiness in the model. Keeping the potential effects of underestimated humidity in mind, which could be more important when high INP concentrations are present, mineral dust is considered as a potential contributor to the extensive cloud development in the following sensitivity study.

\subsection{Dust sensitivity model runs}

Having evaluated the model performance of the control run SMBLK in the previous section, this section is dedicated to the results of the sensitivity study. Again, we begin with the comparison of simulated infrared images to corresponding MSG satellite images and the estimation of upper tropospheric IWC, which is closely related to infrared temperatures. To answer the question whether the interactive dust simulation impacts cloud-top temperature in Fig. 12, we compare the run with climatological dust impact (Fig. 12b, $\mathrm{e}$ and $\mathrm{h}$ ) to the run IINT with fully interactive dust-cloud and dust-radiation effects (Fig. 12c, f and i). The run IINT has more extensive cloud cover due to the impact of the simulated dust plume. In the central and southeastern parts of the domain, which are basically cloud-free in ICLM but cloud-covered in the MSG images (see Fig. 12a, d and g), at least fragmented cloudiness with cloud-top temperatures around $220 \mathrm{~K}$ is present in IINT. However, the representation is still not very realistic, as a coherent cloud shield is still not present (see Fig. 7a, c, e for comparison). For a more quantitative estimation of the differences seen in the simulated images and the satellite images, a threshold temperature $T_{\text {tr }}=240 \mathrm{~K}$ is defined, to calculate the percentage of pixels colder than $T_{\text {tr }}$ in an hourly image series obtained over the period from 4 April at 00:00 UTC to 5 April at 12:00 UTC. We are aware that with this approach the discrimination between cirrus clouds and other cloud types (e.g., convective clouds) cannot be assured and furthermore semi-transparent cirrus clouds with brightness temperatures $T_{\mathrm{b}}>240 \mathrm{~K}$ are not considered. However, given the circumstances of this case study (i.e., the predominant occurrence of very cold widespread cirrus clouds in the satellite images), this should give a rea- 
(a)

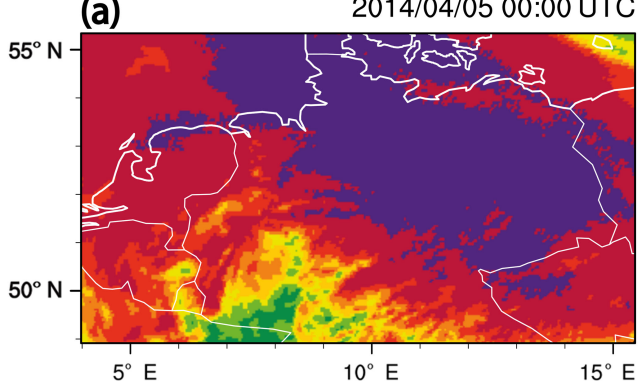

(b)

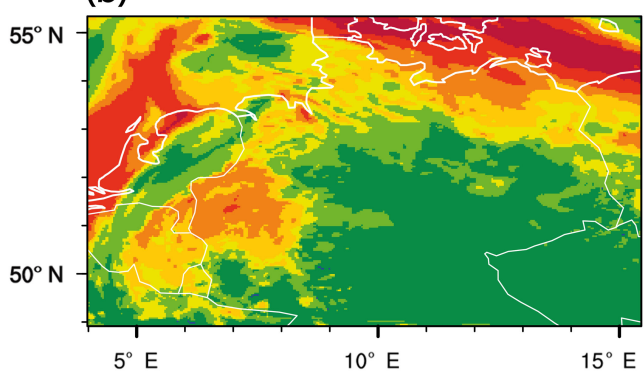

(c)

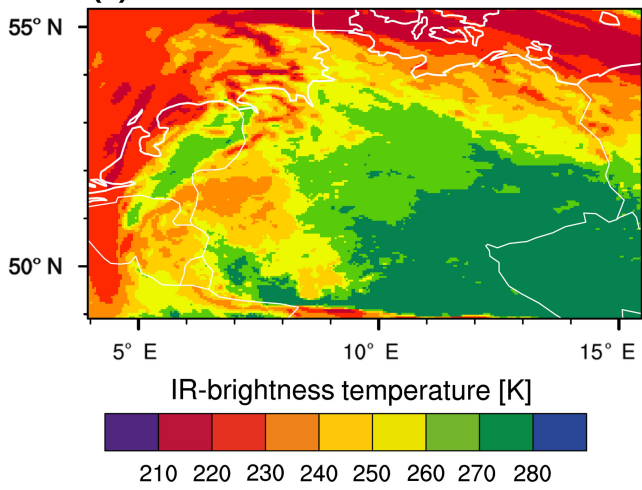

Figure 9. Brightness temperature maps for 5 April at 00:00 UTC: (a) MSG IR $8.7 \mu \mathrm{m}$ channel, (b) infrared simulation for run SMBLK and (c) for run SMBLK with increased humidity.

sonably good quantitative estimate of model performance regarding cirrus cloud representation. For the respective MSG image series, this value is $76 \%$, which highlights that for most of the time and area, the model domain D2 was covered by cirrus clouds. For the run ICLM, this value is $11 \%$, but increases 2 -fold to $21 \%$ with fully interactive dust effects in IINT. Nevertheless, this is still only $28 \%$ of the observed value. In order to trace this sensitivity seen in the infrared images back to cloud microphysics, we compare vertical profiles of IWC for the CloudSat overpass and the time series at the TROPOS site. Figure 13 shows the vertical profiles of the model-to-measurement ratio for the different runs. The CloudSat comparison reveals an expectedly strong sensitivity to mineral dust, as IWC increases between $200 \%$ and $500 \%$ in the run IINT compared to ICLM. In the altitude range between 7 and $11 \mathrm{~km}$, about $10 \%$ of the observed IWC is present in the run ICLM, but this value increases to about
$40 \%$ in the run IINT. The gap to observations is, however, larger in the model near the tropopause at $11.5 \mathrm{~km}$ altitude where it is in the order of 1 order of magnitude (Fig. 13a). At the TROPOS site, a large increase in IWC can be seen in the upper troposphere, when considering interactive dust effects in the model (Fig. 13b). Above $9 \mathrm{~km}$ altitude, only about $5 \%$ of observed IWC is present in the run ICLM with climatological mean dust effect, but this value increases again to roughly $40 \%$ above $9 \mathrm{~km}$ altitude in the run IINT with fully interactive dust effects. Moreover, in IINT, the representation of precipitation is also improved in comparison to the run with single-moment bulk microphysics (see Fig. 11b). The geographical distribution of the precipitation band over northern Germany matches observations better in IINT than in SMBLK. The intense precipitation band seen in the run SMBLK over western Germany is still present in IINT, but shows significantly lower totals of up to $20 \mathrm{~mm}$. Generally, precipitation is better represented by IINT than SMBLK, as domain-wide precipitation is overestimated by only $6 \%$ in IINT but $64 \%$ in SMBLK. The correlation coefficient between observational and model data can be used to estimate the agreement in the geographical distribution of precipitation. The correlation coefficient is $0.50(0.45-0.54)$ in IINT, but only $0.38(0.32-0.43)$ in SMBLK, suggesting a better representation of precipitation in the model run with interactive dust.

To disentangle the different contributing dust effects to the improved cloud representation, we evaluate the additional sensitivity model runs RCLM and CCLM, which have climatological dust-radiation and dust-cloud-activation effects, respectively. Neither run differs significantly from the run IINT in the infrared simulation, suggesting heterogeneous ice nucleation of desert dust being the main contributor to the development of the additional cloudiness. This is also reflected in the CloudSat comparison, as even there, the results of RCLM and CCLM do not show a clear shift towards higher or lower IWC values compared to IINT. Only in the comparison at the TROPOS site is there $80 \%$ less IWC modeled in the mixed-phase cloud region below $6 \mathrm{~km}$ altitude, without radiative effects of the dust plume, in comparison to IINT. Supposedly, dust-radiative effects can affect mixedphase clouds in multiple ways and not only by reducing cloud cover through stabilization of the thermal stratification of the atmosphere. Dust-radiation effects are also evident in the precipitation analysis. Comparing the results with fully interactive dust effects (Fig. 11b) to the results of climatological dust-radiation effects (Fig. 11c), more widespread precipitation is evident over southern Germany in the latter case, which is also reflected in a stronger overestimation of precipitation by $13 \%$ in RCLM versus $6 \%$ in IINT. The layer of strongly absorbing black carbon aerosol at $2 \mathrm{~km}$ altitude (see Fig. 6), which is not represented in the simulations, may have an enforcing effect on thermal stratification, possibly explaining some of the remaining deviations in the model. The reduction of precipitation, however, does not increase 
(a)

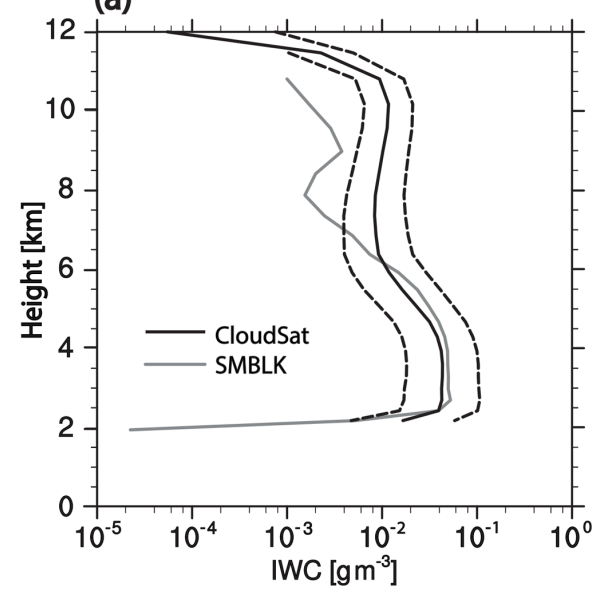

(b)

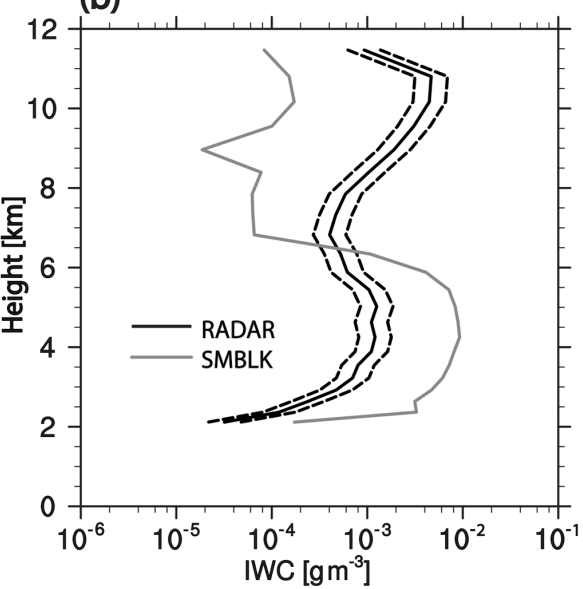

Figure 10. (a) Spatially averaged vertical profiles of IWC retrieved from cloud radar and the model run SMBLK along the CloudSat satellite overpass on 4 April at 12:30 UTC. (b) Similar to (a), but for the time-averaged radar observations and model data at the TROPOS site in Leipzig $\left(51.3^{\circ} \mathrm{N}, 12.3^{\circ} \mathrm{E}\right)$. Absolute values are depicted by full lines, while dashed lines mark the averaged measurement uncertainty of cloud radar retrievals.

the correlation with observations, as correlation coefficients do not differ significantly.

The last sensitivity model run IAIP is used to evaluate the alternative INP parameterization P08 in comparison with the parameterization U17. This is to assess a range of uncertainty due to uncertainties in the freezing properties of mineral dust. In the infrared satellite images, IAIP produces the lowest cirrus cloud cover, with only $7 \%$, which is 3 times lower compared to in IINT. Similarly, in the CloudSat comparison in Fig. 13, IAIP shows the lowest IWC values, except near the tropopause, where the run SMBLK shows the lowest values. Above $6 \mathrm{~km}$ altitude, the difference between IAIP and IINT is particularly large with mostly only $10 \%$ IWC present in IAIP. Even more drastic differences are seen in the comparison at TROPOS at $9 \mathrm{~km}$ altitude, where only $0.1 \%$ of the observed IWC are present in the IAIP run. For the tested INP parameterizations, INAS density as the measure of activity differs by several orders of magnitude in the deposition freezing range (not shown here). These uncertainties obviously affect the model performance to a similar extent to the uncertainties in the representation of mineral dust concentrations in the model.

Table 3 summarizes the most important findings of the sensitivity studies presented in this section.

\subsection{Detailed evaluation of cloud microphysics}

In this section, detailed cloud-microphysics data of the MLCIRRUS flights conducted on 3 and 4 April, respectively, are analyzed. A description of the data sets used and the methodology for data processing are presented in Sect. 2.3.4. In a second part, the ML-CIRRUS data from 3 April is compared to model results, and the sensitivity of modeled ice particle
Table 3. Summary table of the sensitivity study: the cirrus cloud fraction estimation is based on the infrared temperature simulation. IWC in cirrus clouds is the calculated mean IWC inside the layer above $9 \mathrm{~km}$ altitude for both comparisons (CloudSat and TROPOS). Precipitation deviation is calculated as the relative deviation of the sum of modeled $36 \mathrm{~h}$ totals at all stations from the sum of corresponding measurements.

\begin{tabular}{lrl|rr}
\hline \multirow{2}{*}{ Data } & \multicolumn{2}{c|}{ Cirrus } & \multicolumn{2}{c}{ Precipitation } \\
\cline { 2 - 5 } & $\begin{array}{r}\text { Cloud } \\
\text { cover }(\%)\end{array}$ & $\begin{array}{l}\text { IWC } \\
\left(\mathrm{g} \mathrm{m}^{-3}\right)\end{array}$ & $\begin{array}{r}\text { Overesti- } \\
\text { mation }(\%)\end{array}$ & $\begin{array}{r}\text { Corre- } \\
\text { lation }\end{array}$ \\
\hline Observation & 76 & $5 \times 10^{-3}$ & - & - \\
SMBLK & - & $9 \times 10^{-4}$ & 59 & 0.38 \\
ICLM & 11 & $7 \times 10^{-4}$ & 21 & 0.50 \\
IINT & 21 & $2 \times 10^{-3}$ & 6 & 0.50 \\
RCLM & 22 & $2 \times 10^{-3}$ & 13 & 0.53 \\
CCLM & 21 & $2 \times 10^{-3}$ & 8 & 0.49 \\
IAIP & 7 & $3 \times 10^{-4}$ & -4 & 0.34 \\
\hline
\end{tabular}

diameter $D_{\mathrm{i}}$ to heterogeneous ice nucleation of mineral dust is evaluated.

Observed IWC along trajectories of both flights on 3 and 4 April is shown in Fig. 14 underlaid with MSG infrared of cloud cover. Accordingly, on 3 April, HALO did not sample the main cloud shield but broken cirrus clouds at 8 to $12 \mathrm{~km}$ altitude. In addition, a stratiform cloud shield below $7 \mathrm{~km}$ altitude was probed during ascent and descent at start and landing. IWC within cirrus clouds reached up to $10^{-2} \mathrm{~g} \mathrm{~m}^{-3}$ during this flight (Fig. 14a). On 4 April, HALO headed westward to Portugal and passed at an altitude of $9.5 \mathrm{~km}$ through a dense band of cirrus clouds located to the north of the Alps (Fig. 14b). Cloud-top temperatures of this cirrus were 


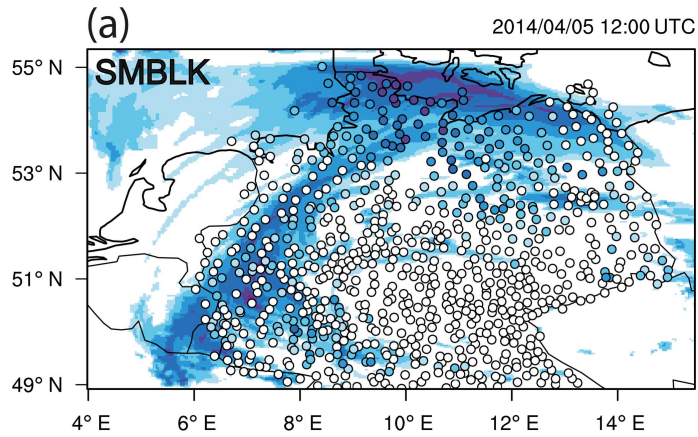

(b)

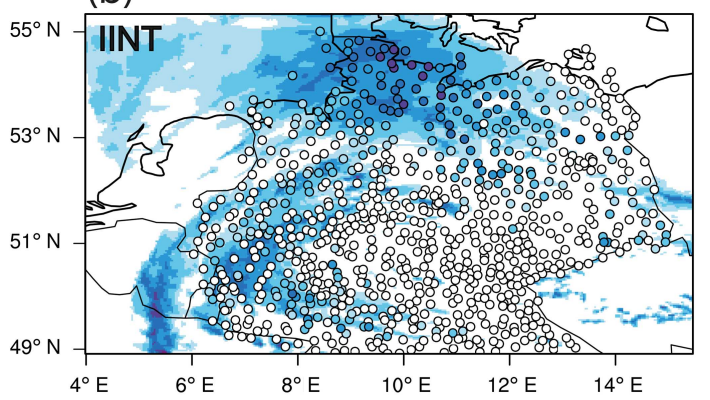

(c)

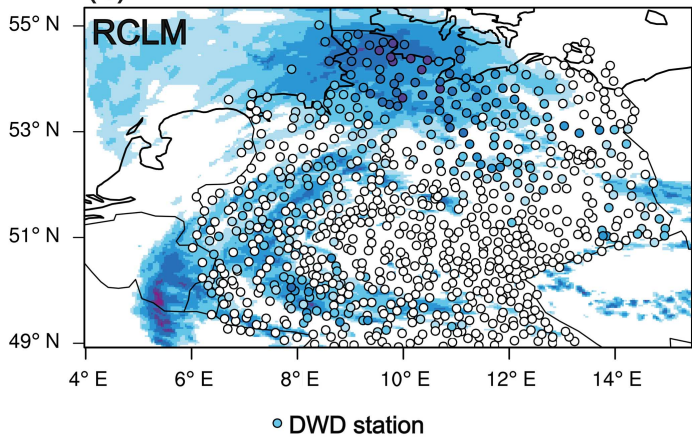

$\circ$ DWD station

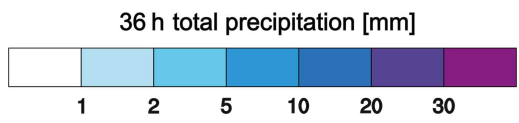

Figure 11. Maps of modeled $36 \mathrm{~h}$ precipitation totals for the different sensitivity model runs (a) SMBLK, (b) IINT and (c) RDLM overlaid with station precipitation measurements (color-coded circles) from DWD stations.

much lower than those of cirrus clouds sampled on 3 April. IWC measured within the clouds on 4 April is partly above $10^{-1} \mathrm{~g} \mathrm{~m}^{-3}$, which is more than 1 order of magnitude higher than on 3 April.

Figure 15 shows ice PSD $\left(\mathrm{m}^{-3} ; d>3 \mu \mathrm{m}\right)$ as colored shadings for both flights averaged along the flight trajectory. Accordingly, on 3 April, the highest particle number concentrations can be found in the smaller size bins with particle diameters lower than $70 \mu \mathrm{m}$ (Fig. 15a). It is remarkable that there are high concentrations of small ice particles (up to $10^{5} \mathrm{~m}^{-3}$ ) at the cloud tops, indicating the influence of aviation-induced contrail cirrus. From about $20 \mu \mathrm{m}$, the de- cline in ice particle number concentrations with increasing diameter is monotonic, with the largest particles having a diameter of around $200 \mu \mathrm{m}$. The number-averaged mean diameter of ice particles $\bar{D}_{\mathrm{N}}$ depicted by the solid line and the top axis in Fig. 15 increases from $25 \mu \mathrm{m}$ at $11 \mathrm{~km}$ altitude to $55 \mu \mathrm{m}$ at $9 \mathrm{~km}$ altitude. This suggests that ice nucleation is predominantly taking place at the cloud tops, where temperatures are the coldest, while after some growth the larger particles settle and are therefore more likely to be found near the cloud base. According to measured prevalent particle sizes, cirrus clouds sampled on 3 April can be classified as cirrus originating in situ (Luebke et al., 2016). For the cloud sampled on 4 April, the main distinguishing characteristics of the clouds sampled on 3 April are the much broader PSD along with much higher particle number concentrations. This is especially pronounced near $20 \mu \mathrm{m}$ with values up to $2 \times 10^{6} \mathrm{~m}^{-3}$, which is close to 200 times the value measured on 3 April. The ice PSD again shows a monotonic decrease in particle number concentrations from the maximum concentration with increasing particle sizes, with no hints of a bimodular structure. $\bar{D}_{\mathrm{N}}$ is between 35 and $40 \mu \mathrm{m}$ in the height range of 8 to $9.5 \mathrm{~km}$, which is slightly lower than $\bar{D}_{\mathrm{N}}$ on 3 April.

On the basis of these observations, the optically dense cirrus cloud sampled on 4 April can also be classified as cirrus originating in situ, as small particles are obviously dominating. At this point the question arises, if aerosol, and in particular, dust concentrations were higher on 4 April, favoring the formation of abundant small ice crystals. The NIXE-CAS measurements for $d<3 \mu \mathrm{m}$ show pronounced differences between the two days. Particle concentrations are higher by an order of magnitude on 4 April $\left(10^{7} \mathrm{~m}^{-3}\right)$ than on 3 April $\left(10^{6} \mathrm{~m}^{-3}\right)$ (Fig. 15). It is also remarkable that there is an abundant presence of relatively large aerosol particles $(d>1 \mu \mathrm{m})$ on 4 April, indicative of mineral dust. The OPC aerosol measurements, obtained on the same aircraft and already used in Sect. 3, support these findings. On 3 April, Fig. 5 shows very low particle number concentrations $(d>500 \mathrm{~nm})$, not higher than the proposed climatological value of $2 \times 10^{5} \mathrm{~m}^{-3}$ above $7.5 \mathrm{~km}$ altitude, revealing quite pristine conditions. On 4 April, however, the situation is markedly different, with particle concentrations reaching up to $8 \times 10^{6} \mathrm{~m}^{-3}$, which is roughly 40 times the climatological mean. Given the fact that dust particles are very efficient INPs, these high concentrations may have increased ice nucleation, leading to high ice particle concentrations and low particle diameters consequently. As for comparison, modeled dust concentrations are shown by the dashed lines in Fig. 5. On 3 April, the model shows high particle number concentrations of more than $10^{7} \mathrm{~m}^{-3}$ up to an altitude of $9 \mathrm{~km}$, which contradicts the measurements, as these show the upper edge of the dust plume located at about $7 \mathrm{~km}$ altitude. This may explain the too-high cloud cover seen in the model run IINT on this day. On 4 April, however, at least in the upper troposphere, there is much a better agreement with the mea- 
(a)

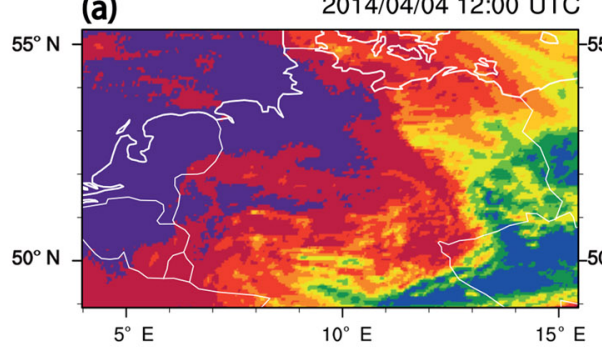

(b) ICLM 2014/04/04 12:00 UTC

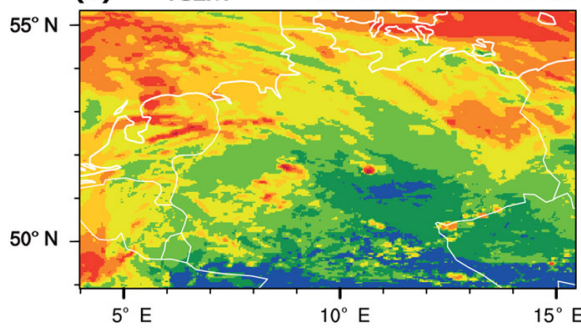

(c) INT

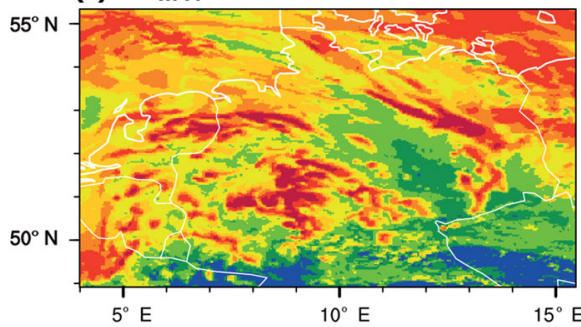

(d)

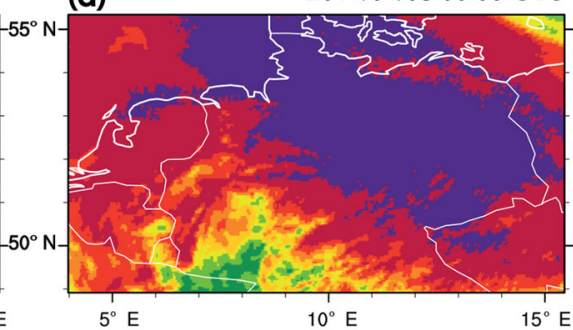

(e) ICLM 2014/04/05 00:00 UTC

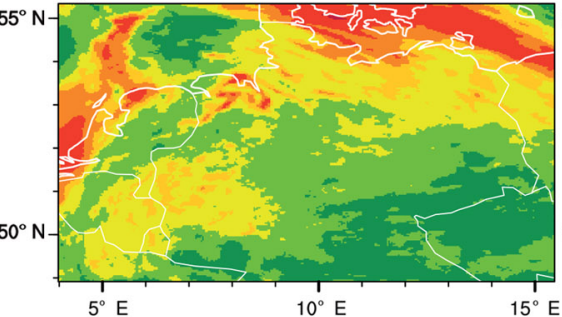

(f) IINT

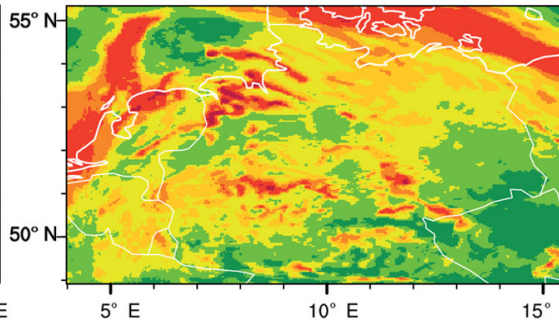

IR-brightness temperature $[\mathrm{K}]$ (g)

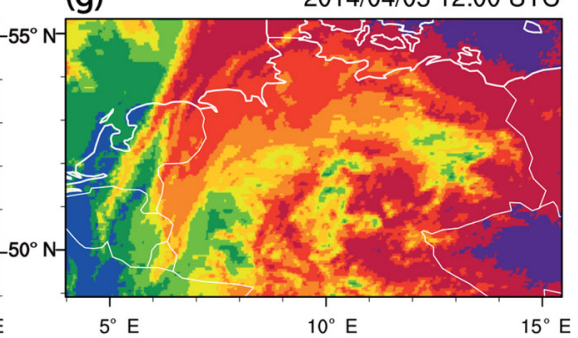

(h) ICLM 2014/04/05 12:00 UTC

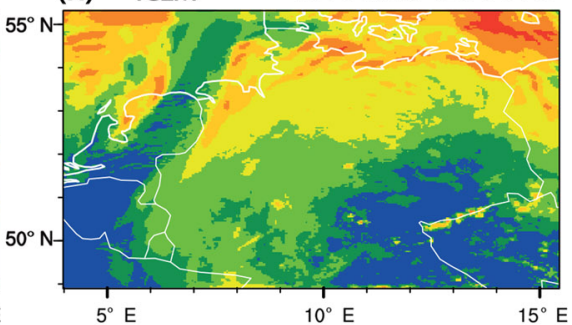

(i) INNT

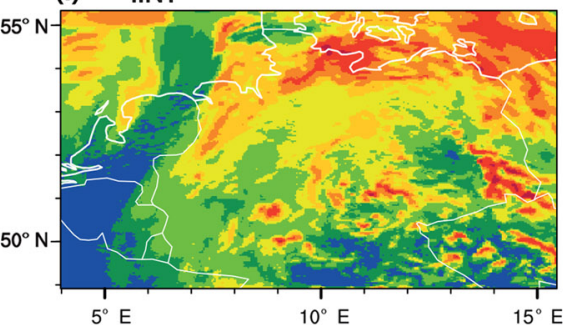

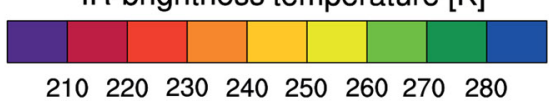

Figure 12. Infrared images of brightness temperature as in Fig. 7 for (a, d, g) MSG IR8.7 satellite data, (b, e, h) the run with climatological mean dust interactions (ICLM) and (c, $\mathbf{f}, \mathbf{i})$ interactive dust effects (IINT).

(a)

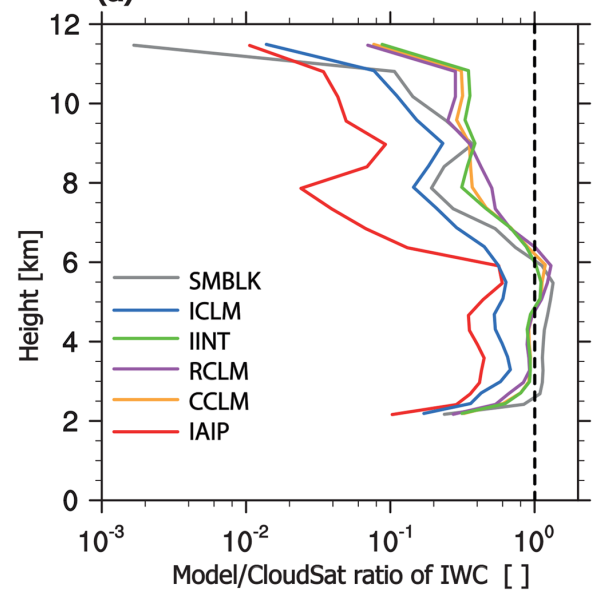

(b)

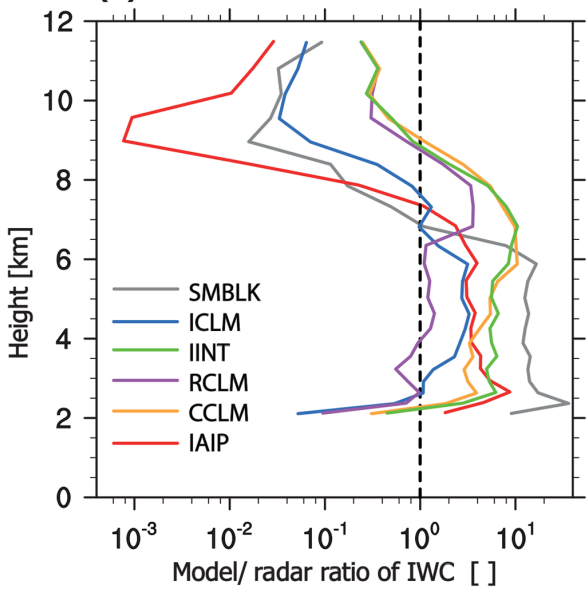

Figure 13. Vertical profiles of model-measurement ratios of IWC for (a) the CloudSat overpass on 4 April at 12:00 UTC and (b) for the time averaged radar observations at TROPOS site in Leipzig $\left(51.3^{\circ} \mathrm{N}, 12.3^{\circ} \mathrm{E}\right)$. 


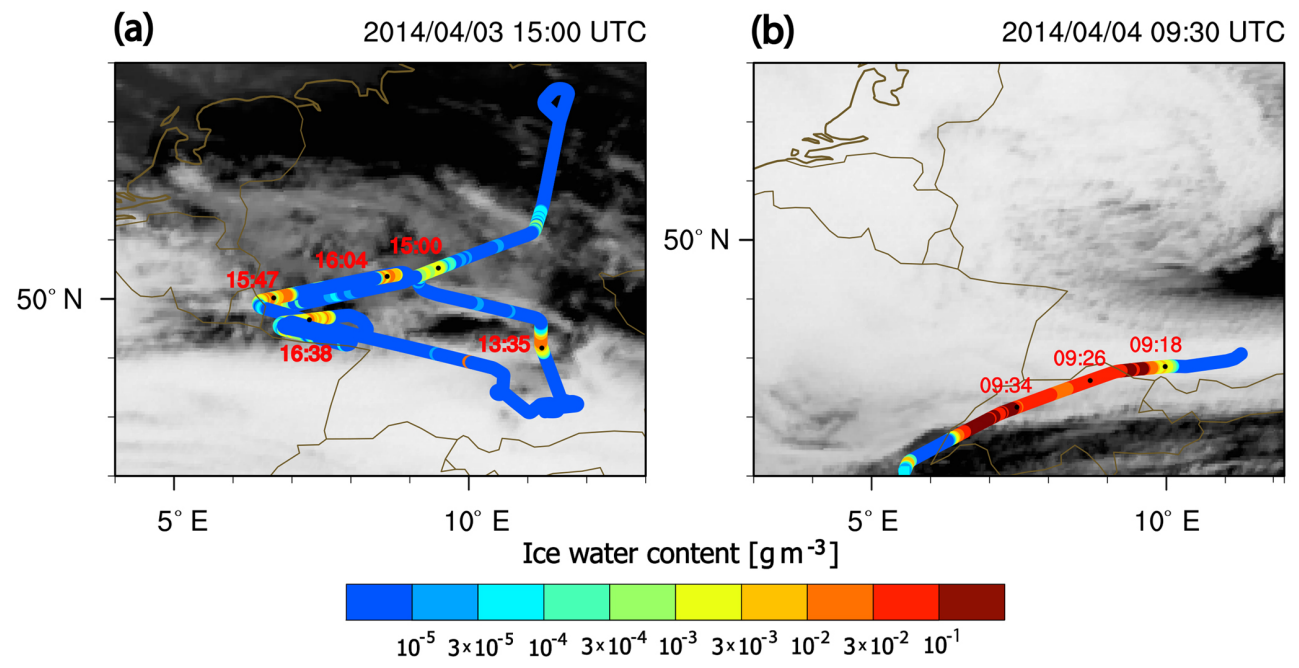

Figure 14. Trajectories of ML-CIRRUS flights conducted (a) on 3 April and (b) on 4 April. The colors of the trajectories represent IWC above $7 \mathrm{~km}$ altitude, which is inferred from the measured ice PSD. In addition, flight time stamps in UTC are shown for both tracks. The background shows MSG SEVIRI IR-8.7 images from (a) on 3 April at 15:00 UTC and (b) on 4 April at 09:00 UTC, indicating differences in cloud cover with cirrus on these days.

(a)

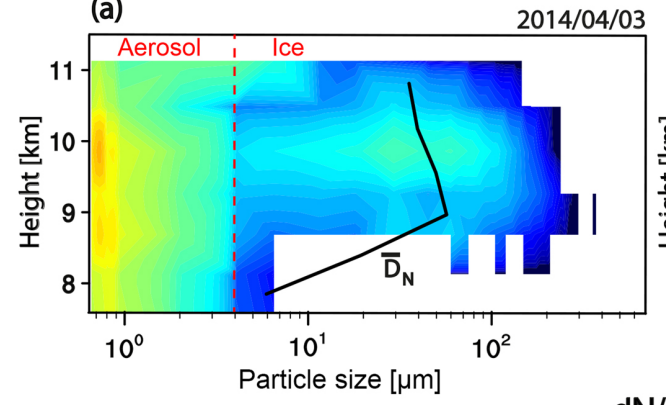

(b)

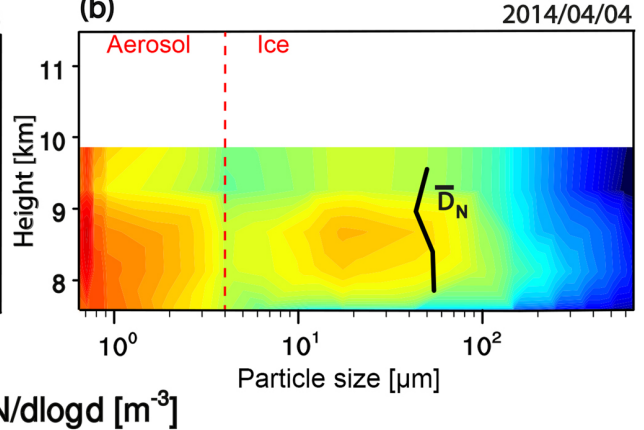

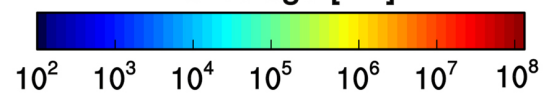

Figure 15. Particle size distributions from measurements with NIXE-CAS and NIXE-CIP (CCP for 4 April) aboard HALO aircraft during ML-CIRRUS campaign on (a) 3 April at 15:00 UTC and (b) on 4 April at 09:30 UTC. The area plots show vertical profiles of the PSD $\mathrm{d} n_{\mathrm{i}} / \mathrm{d} \log d$ on a logarithmic $x$ axis. The red dashed line separates the PSD into the area dominated by aerosol particles $(d<3 \mu \mathrm{m})$ and the area dominated by ice particles $(d>3 \mu \mathrm{m})$. In addition, the full lines show the number-weighted volume mean particle diameter $\bar{D}_{\mathrm{N}}$ for measurements dominated by ice particles.

surements. The modeled dust concentrations are only slightly too low. However, the aircraft did not penetrate layers above $9.5 \mathrm{~km}$ altitude. Yet, it is very likely that the high mineral dust concentrations were mixed by the internal dynamics up to the cloud tops, where ice nucleation is more important.

To assess whether the model shows a similar behavior with enhanced heterogeneous ice nucleation, scatter plots of modeled $D_{\mathrm{i}}$ for the three sensitivity model runs ICLM, IINT and IAIP are plotted in Fig. 16 against the ML-CIRRUS data for 3 April. Furthermore, values of $\bar{D}_{\mathrm{N}}$ as well as $\bar{D}_{\text {IWC }}$ are calculated for all data sets (see Eqs. 13 and 14). In the run ICLM, which considers the climatological dust concentration, data points are shifted to too-high values of modeled vs. measured $D_{\mathrm{i}}$ for high IWC values larger than $10^{-3} \mathrm{~g} \mathrm{~m}^{-3}$, while the contrary is the case for the IWC values lower than $10^{-3} \mathrm{~g} \mathrm{~m}^{-3}$ (Fig. 16a). This asymmetry results in $\bar{D}_{\mathrm{N}}=27 \mu \mathrm{m}$ for the model, which is smaller than the measured value of $38 \mu \mathrm{m}$, but not significantly, given the uncertainties of NIXE-CAS measurements. The contrary is the case for the IWC-weighted average, which puts more weight on the larger ice particles, with $\bar{D}_{\text {IWC }}=72 \mu \mathrm{m}$ in the model and $\bar{D}_{\text {IWC }}=53 \mu \mathrm{m}$ in the measurements. This suggests that at low values of IWC, INPs activate very efficiently in the model with the parameterization U17. However, at larger 

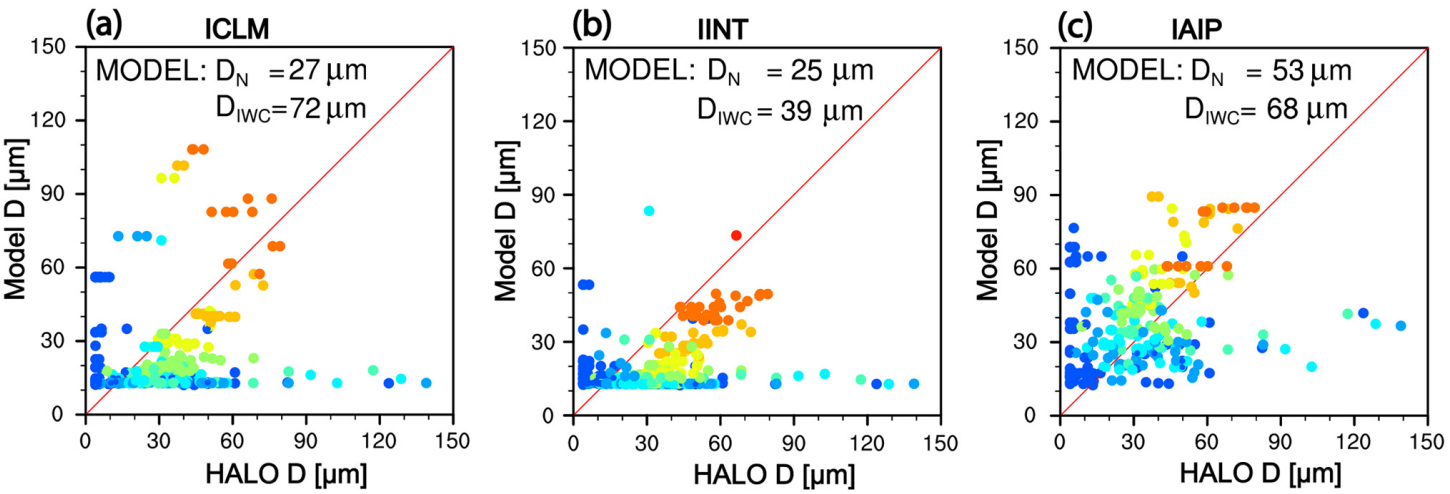

$$
\begin{aligned}
\text { HALO: } & D_{N}=38 \mu \mathrm{m} \\
D_{I W C} & =53 \mu \mathrm{m}
\end{aligned}
$$

Ice water content $\left[\mathrm{gm}^{3}\right]$
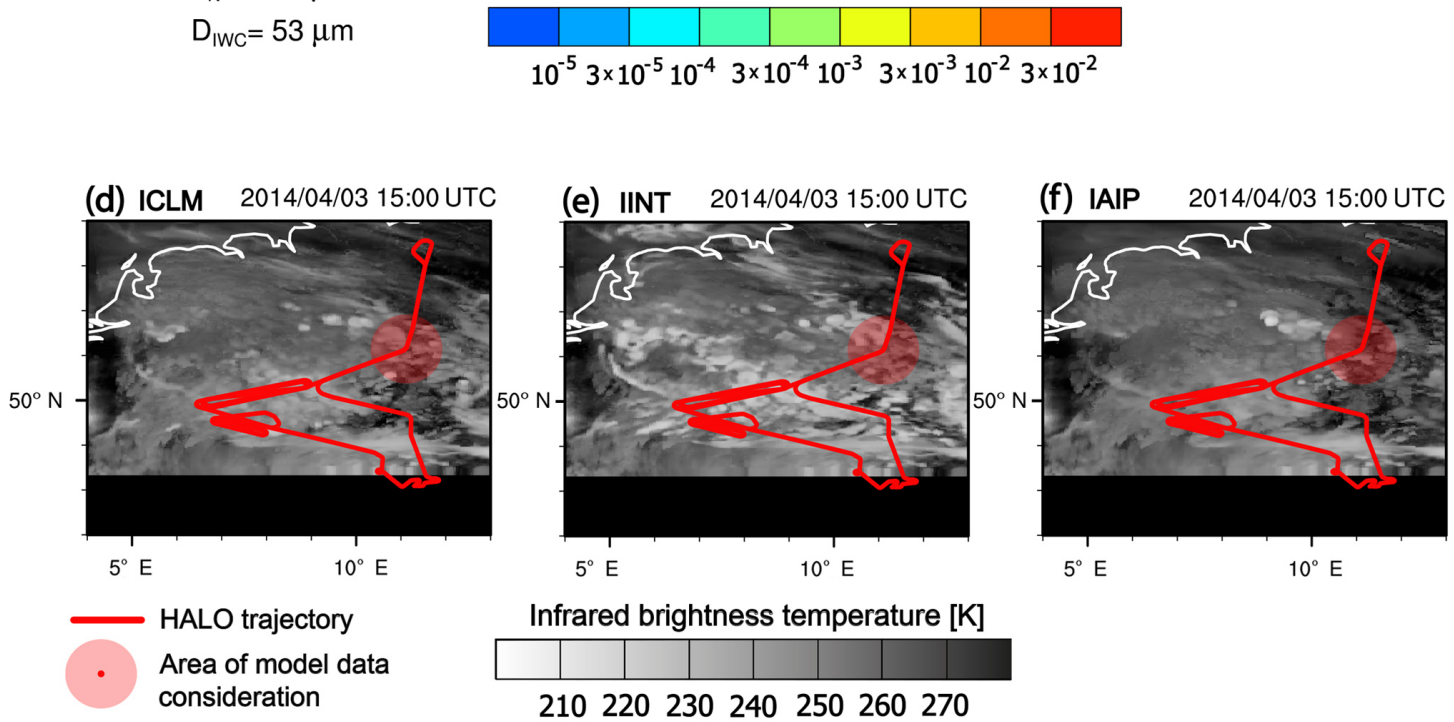

Figure 16. (a, b, c) Scatter plots of ice particle diameter $D_{\mathrm{i}}$ measured aboard HALO during ML-CIRRUS against model results for the model runs ICLM, IINT and IAIP, respectively. $\bar{D}_{\mathrm{N}}$ is the number-weighted average of $D_{\mathrm{i}}, \bar{D}_{\text {IWC }}$ is the IWC-weighted average of $D_{\mathrm{i}}$. (d, e, f) Simulated infrared images for model runs ICLM, IINT and IAIP overlaid with HALO flight track and a reddish shaded circle, within which model data are considered for the comparison.

IWC values, supposedly there are not enough INPs available (constrained by the climatological mean dust concentration) in ICLM for the formation of additional ice crystals. With interactive dust in IINT, we observe a large decrease in $D_{\mathrm{i}}$ in the denser cloud parts with high IWC (Fig. 16b). For most of the data points, simulated $n_{d}$ is above the climatological mean, thus making additional INPs available for ice nucleation in parts of the clouds, while ice nucleation is limited in ICLM. This is reflected in a $46 \%$ decrease in $\bar{D}_{\text {IWC }}$ to $39 \mu \mathrm{m}$, while $\bar{D}_{\mathrm{N}}$ decreases by only $8 \%$ to $25 \mu \mathrm{m}$ compared to ICLM. With the application of the parameterization P08 in the run IAIP, for the whole IWC spectrum, modeled $D_{\mathrm{i}}$ is larger than for the measurements, suggesting the presence of abundant potential INPs, which, however, do not activate efficiently (Fig. 16c).

Figure 16d to $f$ show simulated infrared images for the runs ICLM, IINT and IAIP, respectively. From the sensi- tivity of cold cloud cover to ice nucleation we can conclude that the decrease in $D_{\mathrm{i}}$ in dense cloud regions in response to raised INP concentrations (positive Twomey effect) is the main reason for the additional cirrus cloud formation in the model, as it occurs significantly only in the run IINT. A larger number of ice crystals increases the cloud optical depth (COD), which our model can account for, as the cloud-radiation scheme uses prognostic effective diameters $D_{\mathrm{i}}^{\mathrm{ef}}$ from the two-moment microphysics scheme (see Sect. 2.1.4). This increase in COD increases longwave emissions at the cloud tops, further cooling these regions and enhancing updraughts inside cirro-cumulus clouds. This eventually causes cloud cover to increase in our model. However, cloudy parts which are less dense are not susceptible to this feedback mechanism, as otherwise we would observe an increase in cloud cover using U17 independently of the representation of mineral dust in the model. Thus, higher- 
than-climatological-mean mineral dust concentrations in the model are necessary for additional cirrus cloud formation in this study. Our reasoning is further underpinned by the fact that, without detailed cloud-radiation interactions, no significant sensitivity to mineral dust can be observed in our model runs.

From this analysis, we suggest similar implications for the observed large cloud shield. Fromm et al. (2016) found observational evidence that desert dust decreases ice particle sizes and alters cloud optical properties, as well as the morphology of dust-infused baroclinic cyclone storm clouds. Recently, the WCB transport mechanism was found to be very effective in lifting mineral dust into the upper troposphere where it could interact with cirrus clouds, in a study by Caffrey et al. (2018). Given the obvious analogies to their study, it is likely that the high optical density of the cloud shield in our study was the result of increased ice particle number concentrations due to the presence of mineral dust. Moreover, small ice particles are less likely to precipitate. This, together with the altered optical properties of the cloud shield, may have resulted in the development of the remarkably extensive cloud shield with low cloud-top temperatures, as long as available humidity was not the limiting factor for ice nucleation. At this point, we need to emphasize that one of the main reasons for the misrepresentation of the observed cloud shield in the model is likely the lack of specific humidity in the upper troposphere. With the high dust concentrations in the interactive dust simulation, an increase in humidity likely has a larger positive effect on cloudiness, as in the model runs with the low climatological mean dust concentrations. Interestingly, on the afternoon of 3 April, modeled cloud cover is more extensive than in the satellite images, which is, however, not surprising, given the overestimated mineral dust concentrations and humidity values at this time. For better model results, more realistic meteorological boundary conditions need to be provided. Probably even better would be an extension of the model domain to capture dust emission and transport towards Europe with an interactive dust simulation and two-moment microphysics, as the dust effects on meteorology and cloudiness may impose an important feedback on the fate of the dust plume itself.

\section{Summary and conclusions}

The aim of this study was to model the impact of desert dust on cloud development for the dust outbreak in early April 2014. The regional dust model COSMOMUSCAT was used to simulate dust emission and dust transport from northern Africa toward Europe, as well as dustradiation and dust-cloud interactions over Germany. For reference, a first model run using the operational single-moment bulk microphysics scheme and without dust-radiation and dust-cloud interactions was performed for Germany on a grid with $2.8 \mathrm{~km}$ horizontal spacing over the period 3 April at 12:00 UTC to 5 April at 12:00 UTC. Simulated cloud-top temperatures of this model run were compared to MSG infrared imagery, and modeled IWC to cloud radar retrievals from CloudSat satellite and measured at TROPOS site in Leipzig. In this initial model run, cirrus cloud cover was dramatically underestimated over the $36 \mathrm{~h}$ analyzed period, beginning on 4 April at 00:00 UTC, which coincided with above-average mineral dust concentrations over a major height range of the troposphere. This lack of cirrus was also seen in the comparison of IWC, as only $10 \%$ of observed IWC was reproduced by the model at relevant altitudes. Moreover, modeled precipitation was overestimated by $64 \%$ on average when compared to DWD station records. An underestimation of specific humidity in the upper troposphere was identified as one reason for the absence of cirrus clouds. As another reason, the potential impact of mineral dust on cloudiness during the Saharan dust event is suspected, although was not considered in this SMBLK run. By interactive dust modeling with a two-moment microphysics scheme (Seifert and Beheng, 2006) including dust-radiation, dust-cloud activation and detailed dust-ice nucleation effects, the question of whether cloud and precipitation representation can be improved in the model with this more detailed approach is addressed. Based on the Saharan dust distribution modeled with COSMO-MUSCAT on a domain with $14 \mathrm{~km}$ grid spacing and covering northern Africa and Europe, five sensitivity model runs were performed with COSMOMUSCAT with $2.8 \mathrm{~km}$ horizontal resolution over Germany. The setup of these runs included a run with fully interactive dust effects, a run with a spatially and temporally uniform climatological low average dust concentration prescribed in the radiation and cloud schemes and two runs with climatological dust-radiation effects and dust-cloud activation effects, respectively. While for these model runs the ice parameterization of Ullrich et al. (2017) (U17) was used, an additional fully interactive model run using the parameterization of Phillips et al. (2008) (P08) was performed to assess the uncertainty related to the choice of the ice parameterization.

The evaluation of the modeled dust fields with AERONET data and an aerosol extinction profile retrieved from lidar data at the TROPOS site in Leipzig showed a reasonably good agreement with observations. Uncertainties can be related to the presence of other aerosol components (e.g., black carbon and organic aerosol), which were not simulated with COSMO-MUSCAT.

Comparing the two model runs, one using fully interactive and the other fully prescribed from climatology dust interactions, we found a strong sensitivity of cloud formation to mineral dust concentrations. Cirrus cloud cover doubled and IWC increased by a factor of 2 to 8 inside the cirrus layer, reaching up to about $40 \%$ of the observed values from CloudSat satellite and TROPOS site cloud radar, due to the feedback of the online-simulated dust concentrations.

This sensitivity was found primarily due to increased heterogeneous ice nucleation of mineral dust, as the two addi- 
tional sensitivity model runs using climatological mean mineral dust concentrations, either for radiation interaction or cloud activation, produced the same results for cirrus clouds as with the fully interactive run. Radiative effects of the dust plume predominantly had an impact on precipitation formation in southern Germany. Dust-cloud activation effects were not discernible, which suggests that in our study the assumed aerosol background dominated this process even in the presence of the simulated mineral dust concentrations.

Lastly, the choice of the INP parameterization turned out to be at least as important as the application of a more realistic spatially and temporally varying mineral dust distribution, and the parameterization of Ullrich et al. (2017) led to the best agreement of model results with observations.

Evaluation of ice cloud microphysics in more detail with in situ measurements obtained during the ML-CIRRUS aircraft campaign showed that in general the two-moment microphysics scheme of Seifert and Beheng (2006) along with the modifications done to include detailed dust-cloud interactions was capable of reproducing realistic particle diameters inside cirrus clouds. Homogeneous ice nucleation of liquid aerosol particles was not important in our model, as supersaturation over ice was consistently below the homogeneous freezing threshold given in Kärcher and Lohmann (2002). Thus, heterogeneous ice nucleation controlled particle concentrations and diameters inside cirrus clouds formed in situ. In fact, we could see a strong sensitivity of modeled ice particle sizes to mineral dust concentrations, and the smallest particle diameters with best agreement to measurements were found using interactive dust simulation with the U17 parameterization. The occurrence of the positive Twomey effect in response to high mineral dust concentrations fostered the development of more extensive cirrus clouds in our model due to dust-cloud radiation effects represented in the radiation scheme extended by Dipu et al. (2017).

The improvements seen in our interactive dust-cloud simulations still cannot be considered sufficient for a realistic representation of cirrus cloud cover. The remaining shortcomings are likely caused by the meteorological boundary fields, which underestimated humidity in layers relevant for cirrus cloud formation. Eventually, the combined effects of the dust plume together with realistic humidity values would enhance cirrus cloud development in the model towards a better agreement with the observations. To get better results, either more realistic meteorological boundary fields need to be provided, or new simulations need to be carried out, which use an extended model domain to capture the full evolution of the dust plume with interactive dust effects.

Based on the outcomes of the present sensitivity study, we recommend testing this or similar modeling approaches for other individual cases, which are characterized by extensive cirrus cloud development in association with major desert dust outbreaks in the midlatitudes. It has to be shown, on a statistical basis, whether weather forecast quality during such periods can indeed take advantage of the more detailed but also numerically more expensive interactive weather-dust simulations. For future research, more field studies investigating microphysical properties of cirrus clouds affected by mineral dust could provide valuable information for model evaluation to corroborate our findings. Multispectral satellite observations and derived cloud products can further improve the ability to characterize the spatial distribution of cirrus clouds with lower optical thicknesses to compare their representation in simulations. In addition, further aircraft in situ ice nucleation experiments are needed to reduce the remaining uncertainties in parameterized INP properties of mineral dust and aerosol in general.

Data availability. COSMO-MUSCAT data are available on request. The dust source activation frequency (DSAF) data set is published under https://doi.org/10.14759/41916.2016.1. AERONET coarse-mode AODs are available from http://aeronet.gsfc.nasa.gov. ML-CIRRUS (NIXE-CAPS, NIXE-CIP, OPC, AIMS) measurements and derived data products are provided to the scientific community via the HALO database (HALO consortium, 2017). 


\section{Appendix A: Infrared satellite imagery simulation}

To take advantage of prognostic cloud particle number concentrations in the runs using two-moment microphysics for synthetic infrared image derivation, an appropriate radiative transfer model was constructed in the framework of this study. It is based on absorption and emission of black body radiation at thermodynamic equilibrium and neglects scattering of thermal radiation. The absorption coefficient is calculated as the linear combination of the individual absorption by the modeled six hydrometeor classes, as well as absorption by water vapor. For cloud ice and cloud water, additionally, parameterized subgrid-scale mass contents are considered. The selected PSD for all classes is a generalized gamma function, in accordance with the two-moment microphysics scheme, and parameters are adopted from the currently used version in this study.

For the spherical particle classes graupel, rain and hail, which exclusively contain particles larger by orders of magnitude than the considered wavelength, a constant absorption efficiency of 0.95 is assumed for calculating absorption coefficients based on the geometric cross section. Cloud ice and snow are treated in common, and are assumed to consist of hexagonal plates. For this particle class, the absorption coefficient is parameterized using polynomial approximations to exact Mie calculations (Fu et al., 1998). Therefore, $D_{\mathrm{i}}^{\text {ef }}$ is inferred from $D_{\mathrm{i}}$ by taking the size-dependent linear dimension relationships for hexagonal plates given in Fu et al. (1998). Cloud droplets are treated as spherical particles and the absorption parameterization of Lindner and $\mathrm{Li}$ (2000) is used. To account for water vapor absorption an empirical formulation based on the water vapor mixing ratio, valid for a reference pressure and temperature, is scaled to the actual pressure and temperature value (Chou and Suarez, 1994). The emitted radiation of the Earth's surface is approximated with a surface emissivity ranging from 0.95 for surface temperatures lower than $273 \mathrm{~K}$ to 0.85 for surface temperatures above $280 \mathrm{~K}$. To account for the effects of a slanted satellite viewing angle, the derived optical thicknesses are inversely scaled with the cosine of the satellite viewing angle, calculated for the satellite position $0^{\circ} \mathrm{N}, 0^{\circ} \mathrm{E}$ and the geographical position of the referred model grid point.

To make the infrared simulation also applicable to model data with single-moment microphysics, particle diameters either have to be assumed or parameterized with other prognostic quantities. Here, we assume a constant diameter of $D_{\mathrm{c}}=10 \mu \mathrm{m}$ for cloud droplets and $D_{\mathrm{r}}=10^{3} \mu \mathrm{m}$ for rain droplets. $D_{\mathrm{i}}$ is parameterized with IWC, containing the contributions of modeled $q_{\mathrm{i}}$ and $q_{\mathrm{s}}$. A parameterization was constructed, using ML-CIRRUS data for 3 and 4 April respectively, and is given by the following analytical expression:

$D_{\mathrm{i}}=\left[0.044531 \times \log _{10}(\mathrm{IWC})+1.554498\right]^{0.1}$, where IWC is given in units of grams per meter $\left(\mathrm{g} \mathrm{m}^{-3}\right)$ and $D_{\mathrm{i}}$ in micrometers $(\mu \mathrm{m})$. This expression gives reasonable $D_{\mathrm{i}}$ ranging from $8 \mu \mathrm{m}$ for IWC $=10^{-7} \mathrm{~g} \mathrm{~m}^{-3}$ to $65 \mu \mathrm{m}$ for IWC $=10^{-1} \mathrm{~g} \mathrm{~m}^{-3}$.

For the single-moment bulk microphysics run, and using this parameterization, we compared simulated brightness temperatures with the more comprehensive (treatment of scattering) Radiative Transfer model for TIROS Operational Vertical sounder (RTTOV) model (Saunders et al., 2018) and found a very good agreement with our radiative transfer scheme, as simulated temperatures differed by not more than $5 \mathrm{~K}$, which is in the order of typical uncertainties (Senf and Deneke, 2017). 
Author contributions. MW performed the COSMO-MUSCAT simulations and the analysis, and designed and wrote the manuscript. $\mathrm{BH}$ provided support for the COSMO-MUSCAT simulations and advice from the modeling perspective. $\mathrm{RF}$ and $\mathrm{CH}$ provided code and advice for the INP parameterization, and CE for the cloud droplet activation parameterization. CV, MK, SK, and JS provided access to the ML-CIRRUS aircraft data and discussion on the aspects of the data evaluation. PS and HB provided the lidar and cloud radar data and associated discussion. US, AS and FS contributed to discussions on the project design, and IT provided advice and support throughout the process.

Competing interests. The authors declare that they have no conflict of interest.

Special issue statement. This article is part of the special issue "ML-CIRRUS - the airborne experiment on natural cirrus and contrail cirrus in midlatitudes with the high-altitude long-range research aircraft HALO (ACP/AMT inter-journal SI)". It is not associated with a conference.

Acknowledgements. The authors thank the Deutscher Wetterdienst (DWD) for good cooperation and support. We are grateful for computing time from the German Climate Computing Center (DKRZ). The research leading to these results has partly received funding from ACTRIS-2 in HORIZON 2020 under grant agreement no. 654109 . Christiane Voigt thanks the DFG for funding by within SPP1294 HALO under contract no. VO 1504/4-1 and by the Helmholtz Association under contract no. W2/W3-60. We thank the PI investigators and their staff for establishing and maintaining the AERONET sites used in this investigation. EUMETSAT is acknowledged for providing MSG SEVIRI data. CloudSat data have been provided by the NASA Langley Research Center Atmospheric Science Data Center, and Atmospheric Sounding profiles by the University of Wyoming. We thank an anonymous referee for reviewing the paper, and Editor Darrel Baumgardner for his effort to contribute a timely review by himself and for his thoughtful and valuable review comments.

The publication of this article was funded by the Open Access Fund of the Leibniz Association.

Edited by: Darrel Baumgardner

Reviewed by: Darrel Baumgardner and one anonymous referee

\section{References}

Abdul-Razzak, H. and Ghan, S. J.: A parameterization of aerosol activation: 2. Multiple aerosol types, J. Geophys. Res.-Atmos., 105, 6837-6844, https://doi.org/10.1029/1999JD901161, 2000.

Austin, R. T., Heymsfield, A. J., and Stephens, G. L.: Retrieval of ice cloud microphysical parameters using the CloudSat millimeter-wave radar and temperature, J. Geophys. Res.Atmos., 114, D00A23, https://doi.org/10.1029/2008JD010049, 2009.
Baars, H., Kanitz, T., Engelmann, R., Althausen, D., Heese, B., Komppula, M., Preißler, J., Tesche, M., Ansmann, A., Wandinger, U., Lim, J.-H., Ahn, J. Y., Stachlewska, I. S., Amiridis, V., Marinou, E., Seifert, P., Hofer, J., Skupin, A., Schneider, F., Bohlmann, S., Foth, A., Bley, S., Pfüller, A., Giannakaki, E., Lihavainen, H., Viisanen, Y., Hooda, R. K., Pereira, S. N., Bortoli, D., Wagner, F., Mattis, I., Janicka, L., Markowicz, K. M., Achtert, P., Artaxo, P., Pauliquevis, T., Souza, R. A. F., Sharma, V. P., van Zyl, P. G., Beukes, J. P., Sun, J., Rohwer, E. G., Deng, R., Mamouri, R.-E., and Zamorano, F.: An overview of the first decade of Polly NET: an emerging network of automated Raman-polarization lidars for continuous aerosol profiling, Atmos. Chem. Phys., 16, 5111-5137, https://doi.org/10.5194/acp16-5111-2016, 2016.

Bangert, M., Kottmeier, C., Vogel, B., and Vogel, H.: Regional scale effects of the aerosol cloud interaction simulated with an online coupled comprehensive chemistry model, Atmos. Chem. Phys., 11, 4411-4423, https://doi.org/10.5194/acp-114411-2011, 2011.

Bangert, M., Nenes, A., Vogel, B., Vogel, H., Barahona, D., Karydis, V. A., Kumar, P., Kottmeier, C., and Blahak, U.: Saharan dust event impacts on cloud formation and radiation over Western Europe, Atmos. Chem. Phys., 12, 4045-4063, https://doi.org/10.5194/acp-12-4045-2012, 2012.

Barahona, D. and Nenes, A.: Parameterizing the competition between homogeneous and heterogeneous freezing in cirrus cloud formation - monodisperse ice nuclei, Atmos. Chem. Phys., 9, 369-381, https://doi.org/10.5194/acp-9-369-2009, 2009.

Barkan, J., Alpert, P., Kutiel, H., and Kishcha, P.: Synoptics of dust transportation days from Africa toward Italy and central Europe, J. Geophys. Res.-Atmos., 110, D07208, https://doi.org/10.1029/2004JD005222, 2005.

Baumgardner, D., Jonsson, H., Dawson, W., O'Connor, D., and Newton, R.: The cloud, aerosol and precipitation spectrometer: a new instrument for cloud investigations, Atmos. Res., 59-60, 251-264, https://doi.org/10.1016/S0169-8095(01)00119$3,2001$.

Bégue, N., Tulet, P., Pelon, J., Aouizerats, B., Berger, A., and Schwarzenboeck, A.: Aerosol processing and CCN formation of an intense Saharan dust plume during the EUCAARI 2008 campaign, Atmos. Chem. Phys., 15, 3497-3516, https://doi.org/10.5194/acp-15-3497-2015, 2015.

Berge, E.: Coupling of wet scavenging of sulphur to clouds in a numerical weather prediction model, Tellus B, 45, 1-22, https://doi.org/10.1034/j.1600-0889.1993.00001.x, 1993.

Boose, Y., Sierau, B., García, M. I., Rodríguez, S., Alastuey, A., Linke, C., Schnaiter, M., Kupiszewski, P., Kanji, Z. A., and Lohmann, U.: Ice nucleating particles in the Saharan Air Layer, Atmos. Chem. Phys., 16, 9067-9087, https://doi.org/10.5194/acp-16-9067-2016, 2016.

Bühl, J., Seifert, P., Wandinger, U., Baars, H., Kanitz, T., Schmidt, J., Myagkov, A., Engelmann, R., Skupin, A., Heese, B., Klepel, A., Althausen, D., and Ansmann, A.: LACROS: the Leipzig Aerosol and Cloud Remote Observations System, Proc. SPIE, 6 pp., 8890, https://doi.org/10.1117/12.2030911, 2013.

Caffrey, P. F., Fromm, M. D., and Kablick, G. P.: WRF-Chem Simulation of an East Asian Dust-Infused Baroclinic Storm (DIBS), J. Geophys. Res.-Atmos., 123, 6880-6895, 2018. 
Carslaw, K. S., Boucher, O., Spracklen, D. V., Mann, G. W., Rae, J. G. L., Woodward, S., and Kulmala, M.: A review of natural aerosol interactions and feedbacks within the Earth system, Atmos. Chem. Phys., 10, 1701-1737, https://doi.org/10.5194/acp10-1701-2010, 2010.

Chaboureau, J., Richard, E., Pinty, J., Flamant, C., Girolamo, P. D., Kiemle, C., Behrendt, A., Chepfer, H., Chiriaco, M., and Wulfmeyer, V.: Long range transport of Saharan dust and its radiative impact on precipitation forecast: a case study during the Convective and Orographically induced Precipitation Study (COPS), Q. J. Roy. Meteor. Soc., 137, 236-251, https://doi.org/10.1002/qj.719, 2011.

Chou, M.-D. M. and Suarez, M. J.: An Efficient Thermal Infrared Radiation Parameterization For Use In General Circulation Models, NASA Tech. Memo. 104606, 3, 1-85, NASA Goddard Space Flight Center, Greenbelt, MD, United States, 1994.

Cotton, R. J. and Field, P. R.: Ice nucleation characteristics of an isolated wave cloud, Q. J. Roy. Meteor. Soc., 128, 2417-2437, https://doi.org/10.1256/qj.01.150, 2002.

DeMott, P. J., Sassen, K., Poellot, M. R., Baumgardner, D., Rogers, D. C., Brooks, S. D., Prenni, A. J., and Kreidenweis, S. M.: African dust aerosols as atmospheric ice nuclei, Geophys. Res. Lett., 30, 14, https://doi.org/10.1029/2003GL017410, 2003.

DeMott, P. J., Prenni, A. J., Liu, X., Kreidenweis, S. M., Petters, M. D., Twohy, C. H., Richardson, M. S., Eidhammer, T., and Rogers, D. C.: Predicting global atmospheric ice nuclei distributions and their impacts on climate, National Academy of Sciences, 107, 11217-11222, https://doi.org/10.1073/pnas.0910818107, 2010.

DeMott, P. J., Prenni, A. J., McMeeking, G. R., Sullivan, R. C., Petters, M. D., Tobo, Y., Niemand, M., Möhler, O., Snider, J. R., Wang, Z., and Kreidenweis, S. M.: Integrating laboratory and field data to quantify the immersion freezing ice nucleation activity of mineral dust particles, Atmos. Chem. Phys., 15, 393-409, https://doi.org/10.5194/acp-15-393-2015, 2015.

Dipu, S., Quaas, J., Wolke, R., Stoll, J., Mühlbauer, A., Sourdeval, O., Salzmann, M., Heinold, B., and Tegen, I.: Implementation of aerosol-cloud interactions in the regional atmosphere-aerosol model COSMO-MUSCAT(5.0) and evaluation using satellite data, Geosci. Model Dev., 10, 2231-2246, https://doi.org/10.5194/gmd-10-2231-2017, 2017.

Doms, G.: A Revised Cloud Microphysical Parameterization for COSMO-LME, COSMO Newsletter, 7, 25-28, available at: http://www.cosmo-model.org/content/model/documentation/ newsLetters/newsLetter07/ (last access: 5 December 2018), 2008.

Doms, G. and Baldauf, M.: A Description of the Nonhydrostatic Regional COSMO-Model Part I: Dynamics and Numerics, Deutscher Wetterdienst, Offenbach, Germany, 2015.

Doms, G., Förstner, J., Heise, E., Herzog, H.-J., Mironov, D., Raschendorfer, M., Reinhardt, T., Ritter, B., Schrodin, R., Schulz, J.-P., and Vogel, G.: A Description of the Nonhydrostatic Regional COSMO Model Part II: Physical Parameterization, Deutscher Wetterdienst, Offenbach, Germany, 2011.

ECMWF: Part IV: Physical Processes in IFS Documentation CY43R3, ECMWF, Reading, UK, 2017.

Engelmann, R., Kanitz, T., Baars, H., Heese, B., Althausen, D., Skupin, A., Wandinger, U., Komppula, M., Stachlewska, I. S., Amiridis, V., Marinou, E., Mattis, I., Linné, H., and Ansmann,
A.: The automated multiwavelength Raman polarization and water-vapor lidar Polly ${ }^{X T}$ : the neXT generation, Atmos. Meas. Tech., 9, 1767-1784, https://doi.org/10.5194/amt-9-1767-2016, 2016.

Fridlind, A. M., Ackerman, A. S., Jensen, E. J., Heymsfield, A. J., Poellot, M. R., Stevens, D. E., Wang, D., Miloshevich, L. M., Baumgardner, D., Lawson, R. P., Wilson, J. C., Flagan, R. C., Seinfeld, J. H., Jonsson, H. H., VanReken, T. M., Varutbangkul, V., and Rissman, T. A.: Evidence for the Predominance of Mid-Tropospheric Aerosols as Subtropical Anvil Cloud Nuclei, American Association for the Advancement of Science, 304, 718-722, https://doi.org/10.1126/science.1094947, 2004.

Fromm, M., Kablick, G., and Caffrey, P.: Dust-infused baroclinic cyclone storm clouds: The evidence, meteorology, and some implications, Geophys. Res. Lett., 43, 12643-12650, https://doi.org/10.1002/2016GL071801, 2016.

Fu, Q., Yang, P., and Sun, W. B.: An Accurate Parameterization of the Infrared Radiative Properties of Cirrus Clouds for Climate Models, J. Climate, 11, 2223-2237, https://doi.org/10.1175/15200442(1998)011<2223:AAPOTI>2.0.CO;2, 1998.

Gillani, N. V., Schwartz, S. E., Leaitch, W. R., Strapp, J. W., and Isaac, G. A.: Field observations in continental stratiform clouds: Partitioning of cloud particles between droplets and unactivated interstitial aerosols, J. Geophys. Res.-Atmos., 100, 1868718706, https://doi.org/10.1029/95JD01170, 1995.

Görsdorf, U., Lehmann, V., Bauer-Pfundstein, M., Peters, G., Vavriv, D., Vinogradov, V., and Volkov, V.: A 35$\mathrm{GHz}$ Polarimetric Doppler Radar for Long-Term Observations of Cloud Parameters-Description of System and Data Processing, J. Atmos. Ocean. Tech., 32, 675-690, https://doi.org/10.1175/JTECH-D-14-00066.1, 2015.

Hallberg, A., Noone, K., Ogren, J., Svenningsson, I., Flossmann, A., Wiedensohler, A., Hansson, H., Heintzenberg, J., Anderson, T. L., Arends, B., and Maser, R.: Phase partitioning of aerosol particles in clouds at Kleiner Feldberg, J. Atmos. Ocean. Chem., 19, 107-127, https://doi.org/10.1007/BF00696585, 1994.

HALO consortium: HALO database, available at: https://halo-db. pa.op.dlr.de/, https://doi.org/10.17616/R39Q0T (last access: 10 December 2018), 2017.

Hande, L. B., Engler, C., Hoose, C., and Tegen, I.: Seasonal variability of Saharan desert dust and ice nucleating particles over Europe, Atmos. Chem. Phys., 15, 4389-4397, https://doi.org/10.5194/acp-15-4389-2015, 2015.

Heinold, B., Helmert, J., Hellmuth, O., Wolke, R., Ansmann, A., Marticorena, B., Laurent, B., and Tegen, I.: Regional modeling of Saharan dust events using LM-MUSCAT: Model description and case studies, J. Geophys. Res.-Atmos., 112, D11, https://doi.org/10.1029/2006JD007443, 2007.

Heinold, B., Tegen, I., Schepanski, K., Tesche, M., Esselborn, M., Freudenthaler, V., Gross, S., Kandler, K., Knipperitz, P., Müller, D., Schladitz, A., Toledano, C., Weinzierl, B., Ansmann, A., Althausen, D., Müller, T., Petzold, A., and Wiedensohler, A.: Regional modelling of Saharan dust and biomass burning smoke, Tellus B, 63, 781-799, https://doi.org/10.1111/j.16000889.2011.00570.x, 2011.

Helmert, J., Heinold, B., Tegen, I., Hellmuth, O., and Wendisch, M.: On the direct and semidirect effects of Saharan dust over 
Europe: A modeling study, J. Geophys. Res.-Atmos., 112, D13, https://doi.org/10.1029/2006JD007444, 2007.

Hiranuma, N., Paukert, M., Steinke, I., Zhang, K., Kulkarni, G., Hoose, C., Schnaiter, M., Saathoff, H., and Möhler, O.: A comprehensive parameterization of heterogeneous ice nucleation of dust surrogate: laboratory study with hematite particles and its application to atmospheric models, Atmos. Chem. Phys., 14, 13145-13158, https://doi.org/10.5194/acp-14-131452014, 2014.

Hobbs, P. V. and Rangno, A. L.: Ice Particle Concentrations in Clouds, J. Atmos. Sci., 42, 2523-2549, https://doi.org/10.1175/15200469(1985)042<2523:IPCIC>2.0.CO;2, 1985.

Hogan, R. J., Mittermaier, M. P., and Illingworth, A. J.: The Retrieval of Ice Water Content from Radar Reflectivity Factor and Temperature and Its Use in Evaluating a Mesoscale Model, J. Appl. Meteorol. Clim., 45, 301-317, https://doi.org/10.1175/JAM2340.1, 2006.

Holben, B., Eck, T., Slutsker, I., Tanré, D., Buis, J., Setzer, A., Vermote, E., Reagan, J., Kaufman, Y., Nakajima, T., Lavenu, F., Jankowiak, I., and Smirnov, A.: AERONET - A Federated Instrument Network and Data Archive for Aerosol Characterization, Remote Sens. Environ., 66, 1-16, https://doi.org/10.1016/S0034-4257(98)00031-5, 1998.

Huneeus, N., Schulz, M., Balkanski, Y., Griesfeller, J., Prospero, J., Kinne, S., Bauer, S., Boucher, O., Chin, M., Dentener, F., Diehl, T., Easter, R., Fillmore, D., Ghan, S., Ginoux, P., Grini, A., Horowitz, L., Koch, D., Krol, M. C., Landing, W., Liu, X., Mahowald, N., Miller, R., Morcrette, J.-J., Myhre, G., Penner, J., Perlwitz, J., Stier, P., Takemura, T., and Zender, C. S.: Global dust model intercomparison in AeroCom phase I, Atmos. Chem. Phys., 11, 7781-7816, https://doi.org/10.5194/acp11-7781-2011, 2011.

Illingworth, A. J., Hogan, R. J., O’Connor, E., Bouniol, D., Brooks, M. E., Delanoé, J., Donovan, D. P., Eastment, J. D., Gaussiat, N., Goddard, J. W. F., Haeffelin, M., Baltink, H. K., Krasnov, O. A., Pelon, J., Piriou, J.-M., Protat, A., Russchenberg, H. W. J., Seifert, A., Tompkins, A. M., van Zadelhoff, G.-J., Vinit, F., Willén, U., Wilson, D. R., and Wrench, C. L.: Cloudnet, B. Am. Meteorol. Soc., 88, 883-898, https://doi.org/10.1175/BAMS-886-883, 2007.

Jacobson, M. Z.: Development and application of a new air pollution modeling system - Part III. Aerosol-phase simulations, Atmos. Environ., 31, 587-608, https://doi.org/10.1016/S13522310(96)00201-4, 1997.

Jonson, J., Bartnicki, J., Olendrzynski, K., Jakobsen, H., and Berge, E.: EMEP Eulerian model for atmospheric transport and deposition of nitrogen species over Europe, Environ. Pollut., 102, 289298, https://doi.org/10.1016/S0269-7491(98)80046-8, 1998.

Kärcher, B. and Lohmann, U.: A Parameterization of cirrus cloud formation: Homogeneous freezing including effects of aerosol size, J. Geophys. Res.-Atmos., 107, AAC9-1-AAC9-10, https://doi.org/10.1029/2001JD001429, 2002.

Kärcher, B. and Lohmann, U.: A parameterization of cirrus cloud formation: Heterogeneous freezing, J. Geophys. Res.-Atmos., 108, D14, https://doi.org/10.1029/2002JD003220, 2003.

Karydis, V. A., Kumar, P., Barahona, D., Sokolik, I. N., and Nenes, A.: On the effect of dust particles on global cloud condensation nuclei and cloud droplet number, J. Geophys. Res.-Atmos., 116, D23, https://doi.org/10.1029/2011JD016283, 2011.

Kaufmann, S., Voigt, C., Heller, R., Jurkat-Witschas, T., Krämer, M., Rolf, C., Zöger, M., Giez, A., Buchholz, B., Ebert, V., Thornberry, T., and Schumann, U.: Intercomparison of midlatitude tropospheric and lower-stratospheric water vapor measurements and comparison to ECMWF humidity data, Atmos. Chem. Phys., 18, 16729-16745, https://doi.org/10.5194/acp-18-167292018, 2018.

Knorr, W. and Heimann, M.: Impact of drought stress and other factors on seasonal land biosphere $\mathrm{CO}_{2}$ exchange studied through an atmospheric tracer transport model, Tellus B, 47, 471-489, https://doi.org/10.3402/tellusb.v47i4.16062, 1995.

Knoth, O. and Wolke, R.: An explicit-implicit numerical approach for atmospheric chemistry-transport modeling, Atmos. Environ., 32, 1785-1797, https://doi.org/10.1016/S1352-2310(97)004767, 1998

Köhler, C. H.: Optical properties of mineral dust aerosol in the thermal infrared, AIP Conf. Proc., 1810, 050001, https://doi.org/10.1063/1.4975513, 2017.

Krämer, M., Rolf, C., Luebke, A., Afchine, A., Spelten, N., Costa, A., Meyer, J., Zöger, M., Smith, J., Herman, R. L., Buchholz, B., Ebert, V., Baumgardner, D., Borrmann, S., Klingebiel, M., and Avallone, L.: A microphysics guide to cirrus clouds - Part 1: Cirrus types, Atmos. Chem. Phys., 16, 3463-3483, https://doi.org/10.5194/acp-16-3463-2016, 2016.

Lee, S. S. and Penner, J. E.: Aerosol effects on ice clouds: can the traditional concept of aerosol indirect effects be applied to aerosol-cloud interactions in cirrus clouds?, Atmos. Chem. Phys., 10, 10345-10358, https://doi.org/10.5194/acp-10-103452010, 2010.

Lindner, T. H. and Li, J.: Parameterization of the Optical Properties for Water Clouds in the Infrared, J. Climate, 13, 1797-1805, https://doi.org/10.1175/15200442(2000)013<1797:POTOPF>2.0.CO;2, 2000.

Luebke, A. E., Afchine, A., Costa, A., Grooß, J.-U., Meyer, J., Rolf, C., Spelten, N., Avallone, L. M., Baumgardner, D., and Krämer, M.: The origin of midlatitude ice clouds and the resulting influence on their microphysical properties, Atmos. Chem. Phys., 16, 5793-5809, https://doi.org/10.5194/acp-16-5793-2016, 2016.

Marcolli, C.: Deposition nucleation viewed as homogeneous or immersion freezing in pores and cavities, Atmos. Chem. Phys., 14, 2071-2104, https://doi.org/10.5194/acp-14-2071-2014, 2014.

Marticorena, B. and Bergametti, G.: Modeling the atmospheric dust cycle: 1. Design of a soil-derived dust emission scheme, J. Geophys. Res.-Atmos., 100, 16415-16430, https://doi.org/10.1029/95JD00690, 1995.

Meyer, J.: Ice Crystal Measurements with the New Particle Spectrometer NIXE-CAPS, available at: https://books.google. de/books?id=dSL6V0ZeDs0C, (last access: 5 December 2018), 2013.

Meyers, M. P., DeMott, P. J., and Cotton, W. R.: New Primary Ice-Nucleation Parameterizations in an Explicit Cloud Model, J. Appl. Meteorol., 31, 708-721, https://doi.org/10.1175/15200450(1992)031<0708:NPINPI>2.0.CO;2, 1992.

Miloshevich, L. M., Vömel, H., Whiteman, D. N., and Leblanc, T.: Accuracy assessment and correction of Vaisala RS92 radiosonde water vapor measurements, J. Geophys. Res.-Atmos., 114, D11, https://doi.org/10.1029/2008JD011565, 2008. 
Mishchenko, M. I., Travis, L. D., and Lacis, A. A.: Scattering, Absorption, and Emission of Light by Small Particles, Cambridge University Press, Cambridge, UK, 2002.

Mitchell, D. L., Lawson, R. P., and Baker, B.: Understanding effective diameter and its application to terrestrial radiation in ice clouds, Atmos. Chem. Phys., 11, 3417-3429, https://doi.org/10.5194/acp-11-3417-2011, 2011.

Müller, T., Schladitz, A., Kandler, K., and Wiedensohler, A.: Spectral particle absorption coefficients, single scattering albedos and imaginary parts of refractive indices from ground based in situ measurements at Cape Verde Island during SAMUM-2, Tellus B, 63, 573-588, https://doi.org/10.1111/j.1600-0889.2011.00572.x, 2011.

Niedermeier, D., Shaw, R. A., Hartmann, S., Wex, H., Clauss, T., Voigtländer, J., and Stratmann, F.: Heterogeneous ice nucleation: exploring the transition from stochastic to singular freezing behavior, Atmos. Chem. Phys., 11, 8767-8775, https://doi.org/10.5194/acp-11-8767-2011, 2011.

Niemand, M., Möhler, O., Vogel, B., Vogel, H., Hoose, C., Connolly, P., Klein, H., Bingemer, H., DeMott, P., Skrotzki, J., and Leisner, T.: A Particle-Surface-Area-Based Parameterization of Immersion Freezing on Desert Dust Particles, J. Atmos. Sci., 69, 3077-3092, https://doi.org/10.1175/JAS-D-11-0249.1, 2012.

O’Neill, N. T., Eck, T. F., Smirnov, A., Holben, B. N., and Thulasiraman, S.: Spectral discrimination of coarse and fine mode optical depth, J. Geophys. Res.-Atmos., 108, D17, https://doi.org/10.1029/2002JD002975, 2003.

Ovtchinnikov, M. and Kogan, Y. L.: An Investigation of Ice Production Mechanisms in Small Cumuliform Clouds Using a 3-D Model with Explicit Microphysics. Part I: Model Description, J. Atmos. Sci., 57, 2989-3003, https://doi.org/10.1175/15200469(2000)057<2989:AIOIPM>2.0.CO;2, 2000.

Phillips, V. T. J., DeMott, P. J., and Andronache, C.: An Empirical Parameterization of Heterogeneous Ice Nucleation for Multiple Chemical Species of Aerosol, J. Atmos. Sci., 65, 2757-2783, https://doi.org/10.1175/2007JAS2546.1, 2008.

Prigent, C., Jiménez, C., and Catherinot, J.: Comparison of satellite microwave backscattering (ASCAT) and visible/near-infrared reflectances (PARASOL) for the estimation of aeolian aerodynamic roughness length in arid and semi-arid regions, Atmos. Meas. Tech., 5, 2703-2712, https://doi.org/10.5194/amt-5-27032012, 2012.

Pruppacher, H. and Klett, J.: Microphysics of Clouds and Precipitation, https://doi.org/10.1007/978-0-306-48100-0, Springer, Dordrecht, Germany, 2010.

Rieger, D., Steiner, A., Bachmann, V., Gasch, P., Förstner, J., Deetz, K., Vogel, B., and Vogel, H.: Impact of the 4 April 2014 Saharan dust outbreak on the photovoltaic power generation in Germany, Atmos. Chem. Phys., 17, 13391-13415, https://doi.org/10.5194/acp-17-13391-2017, 2017.

Ritter, B. and Geleyn, J.-F.: A Comprehensive Radiation Scheme for Numerical Weather Prediction Models with Potential Applications in Climate Simulations, Mon. Weather Rev., 120, 303-325, https://doi.org/10.1175/15200493(1992)120<0303:ACRSFN>2.0.CO;2, 1992.

Rose, T., Crewell, S., Löhnert, U., and Simmer, C.: A network suitable microwave radiometer for operational monitoring of the cloudy atmosphere, Atmos. Res., 75, 183-200, https://doi.org/10.1016/j.atmosres.2004.12.005, 2005.
Salvador, P., Alonso-Pérez, S., Pey, J., Artíñano, B., de Bustos, J. J., Alastuey, A., and Querol, X.: African dust outbreaks over the western Mediterranean Basin: 11-year characterization of atmospheric circulation patterns and dust source areas, Atmos. Chem. Phys., 14, 6759-6775, https://doi.org/10.5194/acp14-6759-2014, 2014.

Saunders, R., Hocking, J., Turner, E., Rayer, P., Rundle, D., Brunel, P., Vidot, J., Roquet, P., Matricardi, M., Geer, A., Bormann, N., and Lupu, C.: An update on the RTTOV fast radiative transfer model (currently at version 12), Geosci. Model Dev., 11, 27172737, https://doi.org/10.5194/gmd-11-2717-2018, 2018.

Schepanski, K., Heinold, B., and Tegen, I.: Harmattan, Saharan heat low, and West African monsoon circulation: modulations on the Saharan dust outflow towards the North Atlantic, Atmos. Chem. Phys., 17, 10223-10243, https://doi.org/10.5194/acp-17-102232017, 2017.

Schumann, U., Graf, K., Bugliaro, L., Wirth, M., Ziereis, H., Giez, A., Jurkat, T., Kaufmann, S., Schlage, R., Zahn, A., Dörnbrack, A., Krämer, M., Minikin, A., and Voigt, C.: Contrail predictions for ML-CIRRUS - Method and Experiences, TAC4, Bad Kohlgrub, DLR FB 2015-38, 132-138, available at: http://elib. dlr.de/97373/ (last access: 5 December 2018), 2016.

Seifert, A. and Beheng, K. D.: A two-moment cloud microphysics parameterization for mixed-phase clouds. Part 1: Model description, Meteorol. Atmos. Phys., 92, 45-66, https://doi.org/10.1007/s00703-005-0112-4, 2006.

Seifert, P., Ansmann, A., Mattis, I., Wandinger, U., Tesche, M., Engelmann, R., Müller, D., Pérez, C., and Haustein, K.: Saharan dust and heterogeneous ice formation: Eleven years of cloud observations at a central European EARLINET site, J. Geophys. Res.-Atmos., 115, D20, https://doi.org/10.1029/2009JD013222, 2010.

Senf, F. and Deneke, H.: Uncertainties in synthetic Meteosat SEVIRI infrared brightness temperatures in the presence of cirrus clouds and implications for evaluation of cloud microphysics, Atmos. Res., 183, 113-129, https://doi.org/10.1016/j.atmosres.2016.08.012, 2017.

Shao, Y., Wyrwoll, K.-H., Chappell, A., Huang, J., Lin, Z., McTainsh, G. H., Mikami, M., Tanaka, T. Y., Wang, X., and Yoon, S.: Dust cycle: An emerging core theme in Earth system science, Aeolian Res., 2, 181-204, https://doi.org/10.1016/j.aeolia.2011.02.001, 2011.

Shaw, R. A., Durant, A. J., and Mi, Y.: Heterogeneous Surface Crystallization Observed in Undercooled Water, J. Phys. Chem. B, 109, 9865-9868, https://doi.org/10.1021/jp0506336, 2005.

Sinyuk, A., Torres, O., and Dubovik, O.: Combined use of satellite and surface observations to infer the imaginary part of refractive index of Saharan dust, Geophys. Res. Lett., 30, 2, https://doi.org/10.1029/2002GL016189, 2003.

Smoydzin, L., Teller, A., Tost, H., Fnais, M., and Lelieveld, J.: Impact of mineral dust on cloud formation in a Saharan outflow region, Atmos. Chem. Phys., 12, 11383-11393, https://doi.org/10.5194/acp-12-11383-2012, 2012.

Tegen, I., Hollrig, P., Chin, M., Fung, I., Jacob, D., and Penner, J.: Contribution of different aerosol species to the global aerosol extinction optical thickness: Estimates from model results, J. Geophys. Res., 102, 23895-23915, https://doi.org/10.1029/97JD01864, 1997. 
Tegen, I., Harrison, S. P., Kohfeld, K. I., Prentice, C., Coe, M., and Heimann, M.: Impact of vegetation and preferential source areas on global dust aerosol: Results from a model study, J. Geophys. Res.-Atmos., 107, AAC14-1-AAC14-27, https://doi.org/10.1029/2001JD000963, 2002.

Tucker, C. J., Pinzon, J. E., Brown, M. E., Slayback, D. A., Pak, E. W., Mahoney, R., Vermote, E. F., and Saleous, N. E.: An extended AVHRR 8-km NDVI dataset compatible with MODIS and SPOT vegetation NDVI data, Int. J. Remote Sens., 26, 44854498, https://doi.org/10.1080/01431160500168686, 2005.

Ullrich, R., Hoose, C., Möhler, O., Niemand, M., Wagner, R., Höhler, K., Hiranuma, N., Saathoff, H., and Leisner, T.: A New Ice Nucleation Active Site Parameterization for Desert Dust and Soot, J. Atmos. Sci., 74, 699-717, https://doi.org/10.1175/JASD-16-0074.1, 2017.

Verheggen, B., Cozic, J., Weingartner, E., Bower, K., Mertes, S., Connolly, P., Gallagher, M., Flynn, M., Choularton, T., and Baltensperger, U.: Aerosol partitioning between the interstitial and the condensed phase in mixed-phase clouds, J. Geophys. Res.Atmos., 112, D23, https://doi.org/10.1029/2007JD008714, 2007.

Voigt, C., Schumann, U., Minikin, A., Abdelmonem, A., Afchine, A., Borrmann, S., Boettcher, M., Buchholz, B., Bugliaro, L., Costa, A., Curtius, J., Dollner, M., Dörnbrack, A., Dreiling, V., Ebert, V., Ehrlich, A., Fix, A., Forster, L., Frank, F., Fütterer, D., Giez, A., Graf, K., Grooß, J.-U., Groß, S., Heimerl, K., Heinold, B., Hüneke, T., Järvinen, E., Jurkat, T., Kaufmann, S., Kenntner, M., Klingebiel, M., Klimach, T., Kohl, R., Krämer, M., Krisna, T. C., Luebke, A., Mayer, B., Mertes, S., Molleker, S., Petzold, A., Pfeilsticker, K., Port, M., Rapp, M., Reutter, P., Rolf, C., Rose, D., Sauer, D., Schäfler, A., Schlage, R., Schnaiter, M., Schneider, J., Spelten, N., Spichtinger, P., Stock, P., Walser, A., Weigel, R., Weinzierl, B., Wendisch, M., Werner, F., Wernli, H., Wirth, M., Zahn, A., Ziereis, H., and Zöger, M.: ML-CIRRUS: The Airborne Experiment on Natural Cirrus and Contrail Cirrus with the High-Altitude Long-Range Research Aircraft HALO, B. Am. Meteorol. Soc., 98, 271-288, https://doi.org/10.1175/BAMS-D-15-00213.1, 2017.

Wagner, R., Bunz, H., Linke, C., Möhler, O., Naumann, K.-H., Saathoff, H., Schnaiter, M., and Schurath, U.: Chamber Simulations of Cloud Chemistry: The AIDA Chamber, Nato Science Series: IV: Earth and Environmental Science, 62, 67-82, https://doi.org/10.1007/1-4020-4232-9_5, 2006.
Wang, H., Shi, G., Zhu, J., Chen, B., Che, H., and Zhao, T.: Case study of longwave contribution to dust radiative effects over East Asia, Chinese Sci. Bull., 58, 3673-3681, https://doi.org/10.1007/s11434-013-5752-z, 2013.

Weigel, R., Spichtinger, P., Mahnke, C., Klingebiel, M., Afchine, A., Petzold, A., Krämer, M., Costa, A., Molleker, S., Reutter, P., Szakáll, M., Port, M., Grulich, L., Jurkat, T., Minikin, A., and Borrmann, S.: Thermodynamic correction of particle concentrations measured by underwing probes on fast-flying aircraft, Atmos. Meas. Tech., 9, 5135-5162, https://doi.org/10.5194/amt-95135-2016, 2016.

Wolke, R., Knoth, O., and Münzenberg-St.Denis, A.: Online Coupling of Multiscale Chemistry-Transport Models with NonHydrostatic Meteorological Models, 769-770, Springer, Boston, MA, https://doi.org/10.1007/978-1-4615-4153-0_98, 2000.

Wolke, R., Knoth, O., Hellmuth, O., Schröder, W., and Renner, E.: The parallel model system LM-MUSCAT for chemistrytransport simulations: Coupling scheme, parallelization and applications, Advances in Parallel Computing, 13, 363-369, https://doi.org/10.1016/S0927-5452(04)80048-0, 2004.

Wolke, R., Schröder, W., Schrödner, R., and Renner, E.: Influence of grid resolution and meteorological forcing on simulated European air quality: A sensitivity study with the modeling system COSMO-MUSCAT, Atmos. Environ., 53, 110-130, https://doi.org/10.1016/j.atmosenv.2012.02.085, 2012.

Zhang, D., Wang, Z., Kollias, P., Vogelmann, A. M., Yang, K., and Luo, T.: Ice particle production in mid-level stratiform mixed-phase clouds observed with collocated ATrain measurements, Atmos. Chem. Phys., 18, 4317-4327, https://doi.org/10.5194/acp-18-4317-2018, 2018.

Zhang, L., Gong, S., Padro, J., and Barrie, L.: A size-segregated particle dry deposition scheme for an atmospheric aerosol module, Atmos. Environ., 35, 549-560, https://doi.org/10.1016/S13522310(00)00326-5, 2001.

Zhao, B., Gu, Y., Liou, K., Wang, Y., Liu, X., Huang, L., Jiang, J. H., and $\mathrm{Su}, \mathrm{H} .:$ Type-Dependent Responses of Ice Cloud Properties to Aerosols From Satellite Retrievals, Geophys. Res. Lett., 45, 3297-3306, https://doi.org/10.1002/2018GL077261, 2018. 